\title{
Nanoparticles in Medicine: A Focus on Vascular Oxidative Stress
}

\author{
M. D. Mauricio, ${ }^{1}$ S. Guerra-Ojeda, ${ }^{1}$ P. Marchio, ${ }^{1}$ S. L. Valles, ${ }^{1}$ M. Aldasoro $\mathbb{D},{ }^{1}$ \\ I. Escribano-Lopez, ${ }^{2}$ J. R. Herance, ${ }^{3}$ M. Rocha, ${ }^{2}$ J. M. Vila $\mathbb{D}^{1},{ }^{1}$ and V. M. Victor $\mathbb{D}^{1,2}$ \\ ${ }^{1}$ Department of Physiology, Faculty of Medicine and Odontology, Universitat de Valencia and Institute of Health Research INCLIVA, \\ Valencia, Spain \\ ${ }^{2}$ Service of Endocrinology, University Hospital Doctor Peset, Foundation for the Promotion of Health and Biomedical Research in the \\ Valencian Region (FISABIO), Valencia, Spain \\ ${ }^{3}$ Medical Molecular Imaging Research Group, Vall d'Hebron Research Institute (VHIR), CIBBIM Nanomedicine, Passeig de la \\ Vall d'Hebron, Barcelona, Spain
}

Correspondence should be addressed to J. M. Vila; vila@uv.es and V. M. Victor; vmviktor@gmail.com

Received 3 May 2018; Revised 26 July 2018; Accepted 19 August 2018; Published 26 September 2018

Academic Editor: María Monsalve

Copyright @ 2018 M. D. Mauricio et al. This is an open access article distributed under the Creative Commons Attribution License, which permits unrestricted use, distribution, and reproduction in any medium, provided the original work is properly cited.

\begin{abstract}
Nanotechnology has had a significant impact on medicine in recent years, its application being referred to as nanomedicine. Nanoparticles have certain properties with biomedical applications; however, in some situations, they have demonstrated cell toxicity, which has caused concern surrounding their clinical use. In this review, we focus on two aspects: first, we summarize the types of nanoparticles according to their chemical composition and the general characteristics of their use in medicine, and second, we review the applications of nanoparticles in vascular alteration, especially in endothelial dysfunction related to oxidative stress. This condition can lead to a reduction in nitric oxide (NO) bioavailability, consequently affecting vascular tone regulation and endothelial dysfunction, which is the first phase in the development of cardiovascular diseases. Therefore, nanoparticles with antioxidant properties may improve vascular dysfunction associated with hypertension, diabetes mellitus, or atherosclerosis.
\end{abstract}

\section{Introduction}

The emergence of nanotechnology and its convergence with other disciplines such as biomaterial science, cell and molecular biology, and medicine, referred to as nanomedicine, have drawn the attention of biomedical research due to its potential applications in the diagnosis and treatment of diseases. Nanoparticles (NPs) are the main system used in nanomedicine, as theranostic agents with high molecular specificity [1-3]. Due to their size $(1-100 \mathrm{~nm})$, nanoparticles have a large surface area-to-volume ratio, which allows them to absorb high quantities of drugs [4] and to be spread easily throughout the bloodstream [5]. Their larger surface area gives them unique characteristics, as it improves their mechanical, magnetic, optical, and catalytic properties, thus increasing their potential pharmacological use [4].

Studies on the potential effects and benefits of NPs in diseases involving oxidative stress are receiving growing attention. Cardiovascular risk factors such as hypercholesterolemia or hypertension promote the generation of reactive oxygen species (ROS), which leads to the oxidative stress seen in inflammatory diseases such as atherosclerosis [6]. Therefore, the maintenance and optimization of antioxidant defences can minimize side effects. In this sense, nanoparticles are of great interest, because of their antioxidant properties and easy internalization by the cells.

In this review, we discuss the main mechanisms of oxidative stress implicated in the development and progression of vascular diseases. We also summarize current knowledge in relation to each pathway and mention some examples of the use of NPs as theranostic agents.

\section{Nanoparticles in Medicine}

2.1. General Characteristics. The rapid development of nanotechnology for biological purposes has had a tremendous impact on medicine. Nanotechnology enables the manufacture 


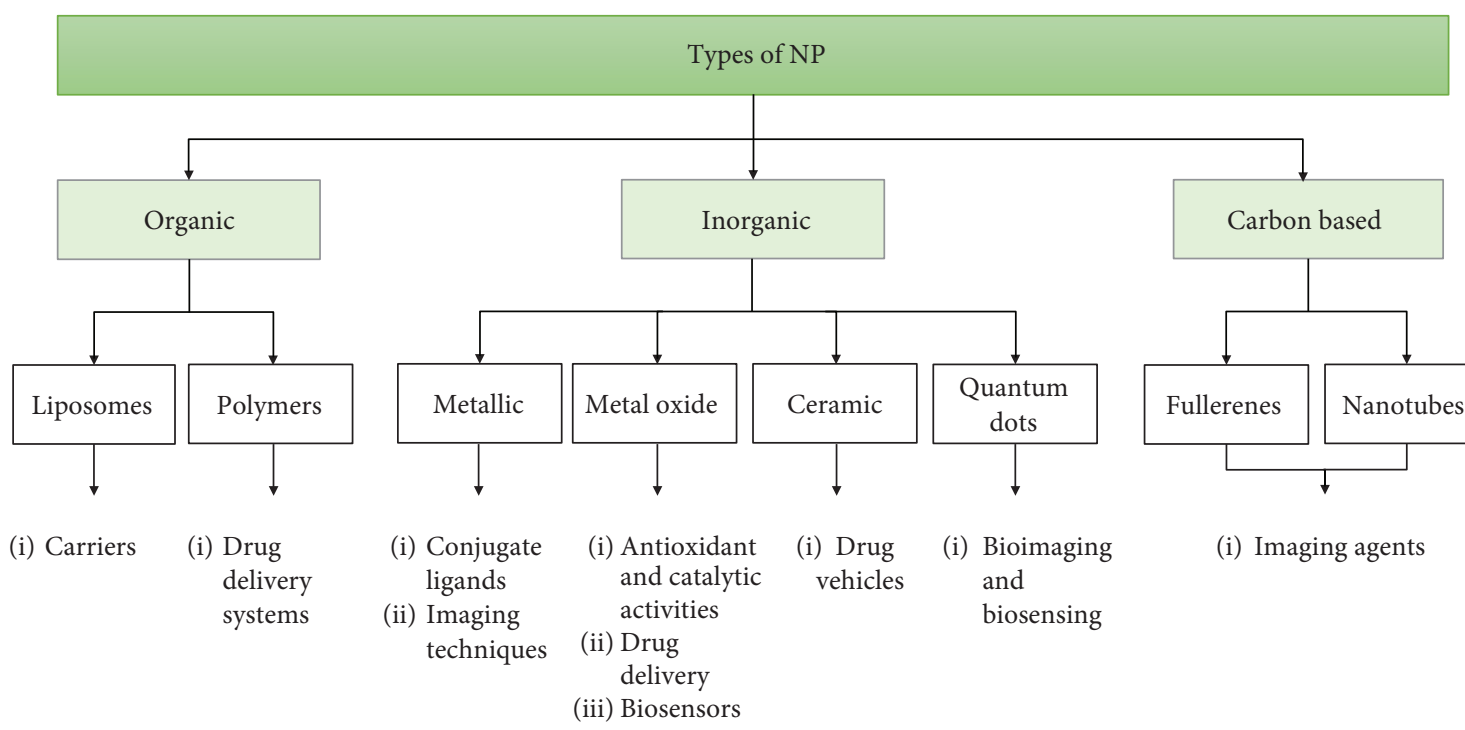

Figure 1: Generalized diagram of the types of nanoparticles and their main biomedical applications. Based on their chemical composition, nanoparticles can be divided into three main groups: organic, inorganic, and carbon-based. Each category includes several types of nanoformulations.

and manipulation of materials on a nanometer scale, thus allowing the development of new tools for the treatment, diagnosis, monitoring, and control of biological systems. This application of nanotechnology in the field of medicine is known as nanomedicine. Nanoparticles, the most widely used nanotechnology platforms in nanomedicine, are particles with two or more dimensions on the nanometer scale, according to the American Society for Testing and Materials (ASTM). These NPs have special enhanced physical and chemical properties compared to their corresponding bulk materials. These properties include a high surface area-to-volume ratio and a unique quantum size effect due to specific electronic structures [7]. In addition to their composition, the properties of NPs depend on their size and shape [8]. Generally, in order to obtain monodispersed NPs and facilitate their internalization by cells, it is necessary to control their size and shape and thus minimize aggregation [9]. It is because of these properties that NPs have been considered as diagnostic, therapeutic, and carrier agents in biomedical applications [1-3]. For instance, some applications are thanked for their surface-mass ratio, which is greater than that of other particles and enables them to bind to, absorb, or carry other molecules [3]. Furthermore, they can be modified or manufactured with two or more materials to improve their physical properties.

2.2. Types of Nanoparticles. Regarding their chemical compounds, NPs can be divided into three main groups: organic nanoparticles (liposomes and polymers), inorganic nanoparticles (metals, metal oxide, ceramic, and quantum dots), and carbon-based nanoparticles [10] (Figure 1). In general, NPs retain the chemical properties of their bulk materials, which can be useful when choosing a specific NP for a biomedical application. The NPs used in nanomedicine include the following.
2.2.1. Liposome Nanoparticles. These are spherical vesicles with a membrane composed of a lipid bilayer containing an aqueous substance. The amphiphilic molecules used for the preparation of these vesicles are similar to biological membranes so as to improve the efficacy and safety of different drugs [11]. The active compound can be hydrophilic and therefore located in the aqueous space or hydrophobic, remaining in the lipid membrane. The synthesis of a liposome depends mainly on the following parameters: (a) the physicochemical characteristics of the material to be entrapped and those of the liposomal compounds; (b) the nature of the medium in which the lipid vesicles are dissolved, the concentration of the entrapped substance, and its potential toxicity; (c) additional processes implicated in during the fabrication, application, or delivery of the vesicles; (d) dispersity, size, and shelf-life of the vesicles for the intended application; and (e) batch-to-batch reproducibility and possibility of large-scale production of safe and efficient liposomal products. Liposomes can be synthetized by sonicating a dispersion of amphipatic lipids, such as phospholipids, in water. In fact, low shear rates can create multilamellar liposomes. The original aggregates have many layers, thus forming progressively smaller, eventually unilamellar liposomes. Sonication is a "gross" method of preparation, as it can damage the structure of the drug to be encapsulated. In addition, there are other methods, such as extrusion and the Mozafari method [12], which are employed to produce materials for human use. Finally, it is important to mention that using lipids other than phosphatidylcholine can greatly facilitate liposome preparation.

Liposomes are mainly used for delivering chemotherapeutic drugs in cancer treatment [13]. They can also incorporate a high number of bioactive materials, including pharmaceutical drugs or food ingredients. Liposomes have great potential applications in nanomedicine, as well as in the food and cosmetics industries, due to their high 
biocompatibility and biodegradability. In recent years, nanoliposome technology has become highly developed, offering real opportunities to food technologists in areas such as the controlled release and encapsulation of food ingredients and improvement of the stability and bioavailability of sensitive compounds. In this way, liposomes are being used as an advanced technology to carry active molecules to specific targets [11].

\subsubsection{Polymeric Nanoparticles. Most polymeric nanoparticles} are known for their biodegradability and biocompatibility, constituting the most commonly used NPs in drug delivery systems [14-16]. This type of nanoparticle can be made from natural polymers, such as chitosan, or synthetic polymers, such as polylactides (PLA), poly (methyl methacrylate) (PMMA), or polyethylene glycol (PEG) [14]. They exhibit great potential for surface modification and have a good pharmacokinetic profile in that their size and solubility can be controlled during manufacture. Polymeric nanoparticles can be prepared by different methods, including two-step procedures based on emulsification, emulsification-solvent evaporation, emulsification-solvent diffusion, and emulsification-reverse salting-out. Additionally, there are methods such as one-step procedures involving nanoprecipitation methods, dialysis and supercritical fluid technology. Among the techniques used to analyse surface properties, we can find energy dispersive spectroscopy (EDS), zeta potential $(\zeta$-potential), X-ray photoelectron spectroscopy (XPS), Fourier transform infrared spectroscopy (FTIR), and Raman. These techniques reveal the chemical composition of polymeric nanoparticle surface and surface functionalization. However, only by using microscopic techniques is it possible to identify morphology and shape. Finally, it is important to take into account that, in order to improve drug-loading efficiency and prolong drug release, the nature of polymer-drug interactions, as well as the polymer type and its physicochemical properties, must be considered [17].

2.2.3. Metallic Nanoparticles. These include precious metals (gold or silver) and magnetic metals (iron oxide or cobalt and manganese doped ferrites). Metallic nanoparticles such as gold $(\mathrm{Au})$ possess unique electronic and optical properties and are nontoxic and biocompatible, and their surface can be modified with other biomolecules due to their negative charge $[18,19]$. A gold surface offers a fantastic opportunity to conjugate ligands such as proteins, oligonucleotides, and antibodies containing functional groups such as phosphines, thiols, mercaptans, and amines, which have a high affinity for the gold surface [20]. Gold nanoconjugates coupled with strongly enhanced localized surface plasmon resonance gold nanoparticles have applications in imaging techniques for the diagnosis of various diseases [21]. In fact, El-Sayed et al. established the use of gold nanoparticles (AuNPs) for cancer imaging by selectively transporting AuNPs into the cancer cell nucleus, thus highlighting the importance of these nanoparticles in biomedicine. In order to do this, they conjugated arginine-aspartic acid-glycine peptide and a nuclear localization signal peptide to a $30 \mathrm{~nm}$ AuNPs. The conjugated arginine-aspartic acid-glycine peptide targets $\alpha \mathrm{v} \beta 6$ integrin receptors on the surface of the cell, whereas the lysine-lysine-lysine-arginine-lysine sequence associates with karyopherins (importins) in the cytoplasm, which enables translocation to the nucleus [22].

2.2.4. Metal Oxide Nanoparticles. These NPs exhibit catalytic and antioxidant activities, chemical stability, optical properties, and biocompatibility, all of which make them suitable for several biomedical applications. The most widely used are iron oxide $\left(\mathrm{Fe}_{3} \mathrm{O}_{4}\right)$, titania $\left(\mathrm{TiO}_{2}\right)$, zirconia $\left(\mathrm{ZrO}_{2}\right)$, and more recently, ceria $\left(\mathrm{CeO}_{2}\right)$ [23]. For instance, titania nanoparticles are incorporated into medical implants due to the biocompatibility of their surface, and ceria nanoparticles are the object of increasing attention because of their catalytic and antioxidant capacity, which allows them to act as antioxidant and anti-inflammatory agents [2]. $\mathrm{TiO} 2$ is a widely studied material due to its biocompatibility, chemical stability, and optical properties, which endow it with important applications, for instance, as a biosensor [24]. Other metal oxide nanoparticles of increasing interest for their potential biomedical applications are cerium oxide $\left(\mathrm{CeO}_{2}\right)$ nanoparticles or nanoceria. Nanoceria have the unique property of being able to switch between oxidation states [2], therefore enhancing their application in oxidative stress-related diseases. Cerium oxide nanoparticles have many defects on their surface, mainly $\mathrm{O}_{2}$ vacancies that result in a combination of coexisting cerium (IV) and cerium (III) oxidation states. This leads to a redox couple, which underlies nanoceria's catalytic activity. These characteristics endow nanoceria with great potential as a biological antioxidant. Other examples of metal oxide nanoparticles are porous silica $\left(\mathrm{SiO}_{2}\right)$. The biomedical applications of these nanoparticles are increasing due to their unique properties, which include large specific surface area, pore volume, controllable particle size, and good biocompatibility. It is due to these properties that mesoporous silica nanoparticles have been investigated for their use in drug delivery in biomedicine and biosensors [25].

Studies have demonstrated the effectiveness of the use of other nanoparticles, such as zinc oxide $(\mathrm{ZnO})$, in drug delivery and bioimaging. One important characteristic of $\mathrm{ZnO}$ nanoparticles is that their surface needs to be modified to protect them in biological systems, as they can be easily dissolved in water and acidic solutions. Furthermore, in order to use $\mathrm{ZnO}$ nanoparticles for fluorescence in imaging, they first need to be doped, as the $\mathrm{ZnO}$ bandwidth is in the UV region and UV light cannot penetrate tissues and can be harmful to cells and tissue [26].

2.2.5. Ceramic Nanoparticles. These are inorganic compounds with porous characteristics that have recently emerged as vehicles for drugs. They are capable of transporting molecules such as proteins, enzymes, or drugs without swelling or compromising their porosity due to the external effects of $\mathrm{pH}$ or temperature [27]. The components most commonly used in ceramic nanoparticles are silica and aluminum. However, the core of these nanoparticles is not limited to these two materials; in fact, they can be composed of a combination of metallic and nonmetallic materials [28]. For instance, $\mathrm{CeO}_{2}$-capped mesoporous silica nanoparticles 
(MSN) have been developed to act as vehicles for drug delivery by releasing $\beta$-cyclodextrin into lung cancer cells [29].

There are a wide range of ceramic materials with multiple applications, including clay minerals, cement, and glass. Biocompatible ceramics, also known as bioceramics, are mainly used for the bone, teeth, and other medical applications. Bioceramics have good biocompatibility, hydrophilicity, osteoconductivity, biodegradability, and reabsorbability. The most widely used ceramic nanobiomaterials are calcium phosphate $(\mathrm{CaP})$, calcium sulphate and carbonate, tricalcium phosphate (TCP), hydroxyapatite (HAP), TCP+HAP, bioactive glasses, bioactive glass ceramics, titania-based ceramics, alumina ceramics, zirconia ceramics, and ceramic polymer composites. All have been applied in nanomedicine, orthopedics, bone regeneration, dentistry, and tissue development, in addition to other biomedical uses in the human body [30].

2.2.6. Quantum Dots. These are nanoparticles made of semiconductor materials with fluorescent properties. In general, quantum dots (QDs) consist of a semiconductor core (e.g., cadmium-selenium (CdSe), cadmium-tellurium (CdTe), indium-phosphate (InP), or indium-arsenate (InAs)), overcoated with a shell (e.g., zinc sulfide $(\mathrm{ZnS})$ ) to improve their optical and physical properties and to prevent leaking of the toxic-heavy metals [31]. These nanoparticles are the most used in bioimaging and biosensing strategies. However, this use requires them to be conjugated to biomolecules, such as proteins, peptides, or oligonucleotides, which enables them to bind to specific sites [32].

QDs' biocompatibility is essential for their biological and biomedical applications. In general, biocompatible QDs can be obtained through three different routes: (1) biomimetic synthesis, through either the use of artificial cellular structures or biomolecules (nucleic acids, peptides, proteins, and enzymes) as templates; (2) biosynthesis, using living organisms in bioreactors; or (3) modifying the surface of QDs derived from chemical synthesis. The biosynthetic approach provides a green pathway for preparing biocompatible QDs without generating toxic products or aggressive reaction conditions, while the surface modification approach can create a high QY on a large scale. One of the most important QDs are gold quantum dots (GQDs), which have similar properties to those of gold nanoparticles; however, unlike other QDs, they do not display fluorescence. Instead, they have colorimetric properties induced by surface plasmon resonance (SPR) depending on solvency, shape, particle size and ligand, surface functionalization, dielectric properties, medium, and agglomeration, which render them highly useful in biological system detection applications, such as DNA sequencing, hybridization assays, genetic disorders, flow cytometry, and immunoblotting [33]. In this sense, Lin et al. [34] synthesized GQDs and functionalized them with a peptide moiety containing a nuclear export signal and caspase-3 recognition sequences in order to use them as protease-mediated cytoplasm-nucleus shuttles for the dynamic monitoring of apoptosis. Once apoptosis is induced, the activated caspase3 cleaves the functional peptide on GQDs, changing the subcellular distribution of GQDs, which are quantified as a function of time by the ratio of photoluminescence in the nucleus to that in the cytoplasm. GQDs function as molecular probes for real-time monitoring of cellular apoptosis, making them ideal for use in cancer.

2.2.7. Carbon-Based Nanoparticles. These include fullerenes and nanotubes. Fullerenes are novel carbon allotropes with a polygonal structure made up exclusively of 60 carbon atoms [35]. Carbon nanotubes are normally manufactured from chemical vapor deposition of graphite. There are two classes of carbon nanotubes: single-walled (SWCNT) and multiwalled (MWCNT), the latter of which exhibits potent antimicrobial properties [36]. Carbon-based nanoparticles are considered of interest in biomedical applications due to their physical properties, including high electrical conductivity and excellent mechanical strength, but they are not biodegradable and require surface modifications, as they have a strong tendency to form large aggregates [37-39].

Carbon nanotubes (CNTs) have outstanding optical properties, which is why they are used as labeling and imaging agents [35]. In fact, CNTs have optical transitions in the nearinfrared (NIR) region, which make them useful in biological tissue and cells, as NIR has lower excitation scattering and greater penetration depth [40]. Furthermore, fluorescence in the NIR region displays much lower autofluorescence than ultraviolet or visible ranges. For all these reasons, CNTs are potent imaging agents with higher resolution and great tissue depth for NIR fluorescence microscopy and optical coherence tomography. In this sense, Cherukuri et al. successfully monitored CNTs in phagocytic cells and in mice (administered intravenously) using NIR fluorescence [41]. However, several studies have reported cytotoxicity induced by CNTs. In this context, Yang et al. have analysed the behaviour of CNTs, such as agglomeration, cellular uptake, or their oxidant activity [42]. The controversial results regarding the biocompatibility of CNTs largely stem from the variability of CNTs (i.e., size, surface properties, charge, and functionalization) and testing subjects (i.e., in vitro vs. in vivo, types of cells, tissues, and animal models employed). In addition, increased cytotoxicity has often been attributed to incomplete removal of metal catalysts used to prepare CNTs [43]. Most in vivo studies using CNTs have shown them to be safe, as toxicity was not reported and there was renal clearance from the body, although small portions of CNTs were found in certain organs, such as the liver, spleen, and lungs [43]. In addition, several in vitro cell culture studies have indicated that the related cytotoxicity is more variable and more pronounced at the cellular level [44].

2.3. Toxicity Concerns. Nanoparticles offer many advantages to the field of medicine. However, the properties that make them so attractive can also contribute to their toxicological profile in biological systems (absorption, distribution, metabolism, and clearance). Toxicological concerns means that size, shape, surface chemistry, and chemical compounds need to be considered during the manufacture of nanoparticles $[10,45]$. These concerns also have a bearing on cellular interactions, the endocytic pathway and the absorption process, and therefore, nanoparticles can exert mechanisms of cytotoxicity that interfere with cellular homeostasis. 
The size of nanoparticles represents one of the crucial factors in their interaction with biological systems and is highly associated with their toxicological effects. Smaller NPs have a greater surface area per unit mass, which allows them to absorb large numbers of chemical molecules, making them more reactive in the cellular environment, thus increasing their toxicological effects [46]. In vitro studies have shown that nanoparticles below $10 \mathrm{~nm}$ are potentially harmful for the lungs due to the large surface area and possible nuclear penetration [47]. Less attention has been paid to the effect of NP shape, possibly due to the fact that most NPs are spherical. In general, the endocytosis of spherical NPs by cells is facilitated more than that of rod-shaped NPs and is relatively less toxic. For instance, gold nanorods show greater potential in cancer hyperthermia than conventional spherical gold nanoparticles, since they can cause breast cancer cell death due to their shape, among other reasons [48].

Some features related to the surface of NPs (surface chemistry and charge) are important in estimating their toxicity and are closely associated to uptake efficiency. For instance, the uptake of NPs made from hydrophobic polymers is greater than that of those made from hydrophilic polymers, which can enhance permeability and retention effect in tumor targeting [49]. Nanoparticle charge can also influence their uptake. Generally, positive NPs are internalized more readily by cells than negative NPs due to the negative charge of the cell membrane. Despite their bactericidal effects, silver nanoparticles have largely detrimental effects in biomedical applications. In this sense, it has been demonstrated that the surface chemistry and charge of these nanoparticles make them susceptible to a greater internalization, therefore rendering them more toxic $[50,51]$.

The toxicity of NPs also depends on the chemical components on their surface. Some metal oxides, such as zinc oxide $(\mathrm{ZnO})$, manganese oxide $\left(\mathrm{Mn}_{3} \mathrm{O}_{4}\right)$, or iron oxide $\left(\mathrm{Fe}_{3} \mathrm{O}_{4}\right)$, have intrinsic toxicity potential $[10,52]$. NPs made from these metal oxides can induce cytotoxic effects that can be reversed by modifying their surface. However, these adverse effects are often very useful in cancer cell therapies [10]. Another chemical component investigated in the context of nanoparticle toxicity is silver $(\mathrm{Ag})$, as it can be widely used and is easily found in the environment. The cytotoxic effects of silver nanoparticles (AgNPs) include induction of ROS and oxidative stress, DNA damage, and apoptosis [53].

The most common route of administration of NPs is intravenous injection. Once they reach the vascular system, they are distributed to various organs and tissues. The physicochemical properties of NPs determine their distribution patterns. Nevertheless, it seems clear that size and surface are the key factors for improved and long-lasting biodistribution. In this sense, smaller nanoparticles $(1-20 \mathrm{~nm})$ tend to infiltrate the organs more than larger ones, and surface modification with hydrophilic polymers such as polyethylene glycol (PEG) enhances their blood circulation time. Regarding biological clearance, renal excretion represents the main route of elimination of exogenous material, such as NPs [54]. Nevertheless, while NPs are in the bloodstream, they can be cleared by other routes, such as disintegration through protein absorption or opsonization-mediated removal by the mononuclear phagocytic system (MPS) [55]. Metallic NPs tend to accumulate in the spleen, liver, and lymph and are able to remain for months due to their nonspecific uptake by MPS [56].

2.4. Advantages of Nanoparticles and Their Potential Role in Oxidative Stress Treatment. Nanoparticles have many potential benefits for medicine, and current clinical applications include diagnosis and therapy. In particular, NPs offer several advantages that make them suitable as drug delivery systems [1-3]. These advantages include (i) easy uptake by the cells due to their small size; (ii) a large surface area-tovolume ratio, which controls the absorption and sustained release of drugs; and (iii) targeted delivery to specific sites. Taking into account these features and considering them from a therapeutic perspective, perhaps the greatest potential of NPs is their use against diseases involving oxidative stress, such as atherosclerosis [6]. Currently, one of the strategies against ROS-whose aim is to maintain and optimize the antioxidant system-is the use of exogenous antioxidants such as vitamin $\mathrm{C}$, vitamin $\mathrm{E}$, or other antioxidants such as $\beta$-carotene. Nevertheless, these molecules have a limited effect, since they are not directly internalized by the cells and sometimes do not reproduce the same results in clinical trials $[57,58]$. Consequently, the development of other exogenous substances with better antioxidant properties is necessary. In this sense, NPs made from metal oxide, such as cerium oxide $\left(\mathrm{CeO}_{2}\right)$ or yttrium oxide $\left(\mathrm{Y}_{2} \mathrm{O}_{3}\right)$, and those that are carbon-based, such as fullerenes, have generated much interest because of their radical-quenching and catalytic properties [59]. For instance, Ciofani et al. found out that cerium nanoparticles or nanoceria were capable of scavenging intracellular ROS, reporting a reduction of $25 \%$ to $50 \%$ of basal ROS in cells exposed to oxidative stress caused by $\mathrm{H}_{2} \mathrm{O}_{2}$ [60]. Therefore, it appears that these types of NPs can be used as ROS scavengers, thus providing a novel strategy against oxidative stress.

It is important to take into account the limitations of the use of small-molecule natural and synthetic antioxidants which include low solubility, poor bioavailability, and their lack of specificity. In this sense, polymeric nanoparticles can be used to encapsulate or incorporate small molecules to provide protection from degradation or to aid in the absorption and distribution of natural antioxidants. Nanoparticles can provide higher solubility to compounds with poor water solubility and enhanced surface functionalization to yield target specificity. Some NPs are known to have prooxidant properties [61], but this action can be avoided by using biodegradable carrier molecules, such as albumin or poly (lactic-co-glycolic) acid (PLGA), which can be broken down by lysosomal or hydrolytic degradation of the matrix polymers [62].

NPs can be carriers of antioxidants, for instance, SODcontaining nanoparticles. In this sense, the application of nanomedicine in ROS-mediated pathologies has dramatically advanced strategies to promote the scavenging of free radicals under oxidative stress, including target specificity, increased cell membrane permeability, and the use of catalytic scavengers. The obvious advantage of using a catalytic 
ROS scavenger is that the compound is not depleted during the reaction and can potentially scavenge numerous ROS molecules, which can enhance their potency with a lower dose. Endogenously, cells use SOD to catalyze the neutralization of $\mathrm{O}_{2}{ }^{\bullet-}$ to $\mathrm{O}_{2}$ and $\mathrm{H}_{2} \mathrm{O}_{2}$. Nanoparticles can be engineered with recombinant SOD conjugation to allow effective cellular delivery of the enzyme under oxidative stress conditions, while protecting the enzyme and avoiding its degradation in the serum [63]. The conjugation of SOD to nanoparticles also promotes blood-brain barrier permeability, which allows these nanoparticles to be used in the context of ischemia/ reperfusion injury in the brain. Upon reaching the cells, the nanoparticle is endocytosed, and the enzyme catalyzes the degradation of $\mathrm{O}_{2}^{-}$. Reddy and Labhasetwar used SOD-conjugated poly (D,L-lactic-co-glycolic acid) (PLGA) nanoparticles to treat ischemia/reperfusion injury in the brains of rats, achieving sustained SOD delivery that enhanced the survival rate and improved their neurological function. Furthermore, an infusion of SOD nanoparticles during reperfusion reduced the infarct size by $65 \%$ compared with a saline control and $40 \%$ compared with SOD delivered in solution. Chen et al. recently engineered silica nanoparticles conjugated with recombinant $\mathrm{Cu} / \mathrm{Zn}$ SOD containing a His-tag domain for attachment to the nanoparticle and a human immunodeficiency virus (HIV) transactivator protein (TAT) domain which allows enhanced transmembrane delivery [64].

Other interesting studies have assessed the use of platinum nanoparticles. Platinum has been used clinically as a chemotherapeutic agent-for example, cisplatin-and in chemistry as a catalyst for hydrogenation and oxidation reactions. It has been shown to catalytically convert $\mathrm{O}_{2}{ }^{-}$to $\mathrm{H}_{2} \mathrm{O}_{2}$ and $\mathrm{H}_{2} \mathrm{O}_{2}$ to $\mathrm{H}_{2} \mathrm{O}$ and $\mathrm{O}_{2}$, which makes it an attractive candidate as a SOD/catalase mimetic for the treatment of oxidative stress-related diseases [65].

Another possibility for antioxidant effects is the use of cerium nanoparticles, which possess catalytic properties similar to those of platinum nanoparticles due to their ability to convert $\mathrm{O}_{2}{ }^{-}$to $\mathrm{O}_{2}$, to generate $\mathrm{Ce}^{3+}$ from $\mathrm{Ce}^{4+}$, and to then autoregenerate $\mathrm{Ce}^{4+}$ from the reduction of $\mathrm{Ce}^{3+}$ or by reacting with $\mathrm{HO}^{\bullet}$. Ceria have also been found to catalyze the degradation of $\mathrm{H}_{2} \mathrm{O}_{2}$ [66], showing the multifaceted mechanism of their antioxidant properties. Furthermore, nanoceria have also been shown to have anti-inflammatory effects by decreasing $\mathrm{NO}$ production from macrophages in mouse cells through a downregulation of iNOS [67]. In another study, ceria were shown to scavenge for $\mathrm{ONOO}^{-}$, a potent RNS generated by the reaction of $\mathrm{O}_{2}^{-}$with $\mathrm{NO}$ [68]. These properties make ceria particularly useful in chronic ROS-mediated inflammatory diseases, where scavenging of NO generated from iNOS in macrophages can halt further inflammatory damage. However, in vitro studies are contradictory, as they provide conflicting evidence of ceria toxicity in different cell lines, perhaps attributable in part to the size and surface area of the ceria particles, with larger particles exhibiting greater toxicity. For example, Estevez et al., [69] evaluated the effects of ceria in an ischemic model of mouse hippocampal brain slices and found approximately a $50 \%$ reduction in cell death, probably due to a marked decrease in the levels of ROS and ONOO-. Ceria can be readily taken up by the cells; however, their tendency to form aggregates in the cytoplasm limits their antioxidant properties [70].

There is another possible application of $\mathrm{H}_{2} \mathrm{O}_{2}$-sensitive nanoparticles in biomedicine. Importantly, ROS production is ubiquitous under physiological conditions, and therefore, a compound that scavenges ROS in a tissue-specific way (e.g., in oxidative tissue) would increase the antioxidant efficacy enormously. In this sense, the development of molecules in response to oxidative stress makes them a useful target for the delivery of antioxidants. For example, Lee et al. [71] developed an antioxidant nanoparticle that is insensitive to $\mathrm{H}_{2} \mathrm{O}_{2}$. This compound consists of a copolyoxalatecontaining vanillyl alcohol (PVAX) particle, and its structure contains peroxalate ester linkages that degrade upon reaction with $\mathrm{H}_{2} \mathrm{O}_{2}$. These effects induce the release of the antioxidant vanillyl alcohol, which decreases ROS production and the inflammatory process associated with it. Furthermore, vanillyl alcohol can also downregulate the expression of cyclooxygenase-2 (COX-2) and iNOS [72].

Another approach for the use of nanoparticles in biomedicine is the use of $\mathrm{pH}$-sensitive nanoparticles. In this sense, it has been described that nitroxyls such as TEMPO are stable radical compounds that are able to scavenge ROS and to form two nonradical species. Another important characteristic of these compounds is their ability to partially mimic SOD, due to their capacity to self-regenerate under oxidative stress conditions. This potential effect of nitroxyls in vitro cannot be replicated in in vivo treatments because they are hipotensive agents and therefore affect the cardiovascular system, especially in a model of ischemia/ reperfusion (I/R). One interesting study by Marushima et al. has identified a micelle nanoparticle with encapsulated 4-amino-TEMPO which is able to protect nitroxyl compounds in vivo [73]. This nanoparticle was shown to decrease infarct size in an animal model of acute cerebrovascular I/R injury. Furthermore, it did not change blood pressure, unlike the free TEMPOL, which decreases blood pressure. In addition, this compound has an in vivo half life longer than that of TEMPOL.

Some NPs are able to release their content in response to a decrease in $\mathrm{pH}$ levels. This is the case of radical-containingnanoparticle (RNP) micelles, which are sensitive to $\mathrm{pH}$. They are able to build polymers under mildly acidic conditions, thus allowing leakage of the TEMPO molecules to the ischemic zone. This therapeutic possibility was developed for the treatment of chronic neurodegenerative disease [74]. The micelle is broken open by the stomach's low $\mathrm{pH}$, and polymer molecules with covalently linked TEMPOL are then absorbed. Overall, the protection and target specificity offered by the micelle's encapsulation of RNPs show great promise for their application as antioxidant therapies for oxidative stress-mediated disease.

Diamond nanoparticles (DNPs) are another interesting type of nanoparticle. DNPs are obtained by explosive detonation and can be treated under Fenton conditions $\left(\mathrm{FeSO}_{4}\right.$ and $\mathrm{H}_{2} \mathrm{O}_{2}$ at acidic $\mathrm{pH}$ ) to obtain purer DNP samples with a small average particle size $(4 \mathrm{~nm})$ and a large population of surface $\mathrm{OH}$ groups (HO-DNPs). Fenton-treated HO-DNPs can 
support gold and platinum nanoparticles of less than $2 \mathrm{~nm}$. In this sense, Martin et al. [75] demonstrated that the resulting materials ( $\mathrm{Au} / \mathrm{HO}-\mathrm{DNP}$ and $\mathrm{Pt} / \mathrm{HO}-\mathrm{DNP}$ ) exhibit a high antioxidant activity against ROS induced in a hepatoma cell line. Furthermore, both $\mathrm{Au} / \mathrm{HO}$ - and $\mathrm{Pt} / \mathrm{HO}-\mathrm{DNPs}$ exhibited good biocompatibility, exhibiting a two-fold higher antioxidant activity with respect to that of glutathione. In another study with ceria-supported gold nanoparticles, they exhibited peroxidase activity and acted as radical traps. In fact, $\mathrm{Au} / \mathrm{CeO}(2)$ showed a remarkable biocompatibility with two human cell lines (Hep3B and HeLa), demonstrated by measuring cellular viability, and proliferation and lack of apoptosis. $\mathrm{Au} / \mathrm{CeO}(2)$ exhibited higher antioxidant activity than glutathione, the main cytosolic antioxidant compound, and its $\mathrm{CeO}_{2}$ carrier. Overall, these results highlight the potential of implementing well-established nanoparticulated gold catalysts with remarkable biocompatibility in cellular biology. A study by Li et al. [76] demonstrated the superoxidescavenging ability of ceria nanoparticles, reporting that nanoceria greater than $5 \mathrm{~nm}$, with different shapes, and with a negligible $\mathrm{Ce}^{3+} / \mathrm{Ce}^{4+}$ ratio can acquire remarkable superoxide-scavenging abilities through electron transfer.

Finally, we would like to highlight the importance of the development of mitochondria-directed nanoparticles. In general, there are many diseases which are related to mitochondrial dysfunction and, therefore, to high ROS production and oxidative stress. Consequently, targeting mitochondria to deliver antioxidants can decrease ROS formation and maintain cell function [77-79]. For example, triphenylphosphonium (TPP) is a molecule capable of crossing cell membranes and can accumulate in mitochondria due to its lipophilic cation. In one study, Marrache and Dhar designed a combination of conjugated PLGA-b-poly (ethylene glycol) (PEG) nanoparticles with TPP-enhancing antioxidant protection and which improved the sitedirected delivery of mitochondria-targeting chemotherapeutics [80]. In said study, PLGA-b-PEG-TPP nanoparticles were loaded with curcumin, a known antioxidant with important therapeutic effects in different diseases, in order to deliver them more effectively to human neuroblastoma cells. This alternative therapy for mitochondrial-directed nanoparticles is a novel approach for the site-specific delivery of ROS scavengers to combat oxidative stress and mitochondrial dysfunction in multiple diseases and therefore reduce the risk-to-benefit ratio.

In conclusion, as a whole, the aforementioned evidence endorses nanoparticles as a promising antioxidant therapy, either for use as carriers of antioxidants or due to their own antioxidant activity.

\section{Targeting Vascular Oxidative Stress Using Nanoparticles}

Oxidative stress is characterized by an increase of reactive oxygen and nitrogen species (RONS) derived from the physiological process of cellular oxidation. In healthy conditions, the antioxidant system counterbalances an excess of RONS in order to maintain the equilibrium of the organism. The imbalance in favour of oxidative stress is related to several pathological conditions, such as vascular dysfunction, characterized by impaired endothelial NO bioavailability and an impairment in vasodilation response, and proinflammatory states. However, the interaction among vascular dysfunction, inflammation, and oxidative stress is not fully understood.

Sources of reactive oxygen species (ROS) in the vascular wall include NADPH oxidase (Nox) [81], uncoupled endothelial NO synthase (eNOS) [82], xanthine oxidase (XO) [83], and mitochondrial respiratory chain enzymes [84]. Under physiological conditions, Nox prevails, and some interactions have been described between Nox and other oxidant mechanisms. In line with this, NADPH oxidase is related to an increase in the activity of xanthine oxidase, eNOS uncoupling, and mitochondrial ROS production [84]. It is noteworthy that angiotensin II (AT II) is related to ROS production at the vascular level by increasing the expression of Nox [85] and xanthine oxidase [86] and reducing the antioxidant system thioredoxin [87]. Therefore, in the present review, we also focus on the renin-angiotensin system, since it is implicated in the vascular complications related to oxidative stress.

Blood flow exerts a frictional force on vascular endothelial cells, namely, hemodynamic shear stress, which is related to the release of ROS [88]. Under physiological conditions (regular flow pattern), shear stress releases endothelial nitric oxide (NO) from L-arginine by eNOS. NO is a potent vasodilator [89] that inhibits platelet adhesion and aggregation [90], vascular smooth muscle proliferation [91], and exerts antiatherogenic effects [92]. Superoxide anion $\left(\mathrm{O}_{2}^{-}\right)$, the most common ROS, interacts with NO to generate peroxynitrite $\left(\mathrm{ONOO}^{-}\right)$, considered a reactive nitrogen species (RNS) [93]. Although this does not happen under normal conditions, because the production of ROS is limited, in conditions of vascular oxidative stress, the increase of ROS reduces the bioavailability of NO. The vascular wall also contains antioxidant systems, such as superoxide dismutase (SOD), catalase, glutathione peroxidases, thioredoxin system, and peroxideroxins.

In this sense, we will now describe each oxidant or antioxidant system, and we summarize some of the research about nanoparticles which affect these systems at a vascular level.

3.1. NADPH Oxidase in the Vascular Wall. NADPH oxidases use NADPH to reduce $\mathrm{O}_{2}$ to $\mathrm{O}_{2}{ }^{-}$. Nox $1,2,4$, and 5 are expressed in the vascular wall; Nox2 [94] is located mainly in endothelial cells and Nox1 [95] in vascular smooth muscle cells (VSMC), whereas Nox 4 and Nox 5 can be found in both cell types [96]. Nox family enzymes are implicated in some vascular diseases, such as hypertension, atherosclerosis, and vascular diabetic complications, and as a result, their role in vascular pathologies has received much attention. Nox 2 gene expression is inducible and increases in response to AT II in some vessels, such as the aorta or resistance arteries [96]. Nox 1 expression is induced by prostaglandin F2alpha, plateletderived growth factor, and also by AT II in vascular smooth muscle [96]. However, the effects of AT II on the activation of Nox 4 expression are contradictory [96]. Little is known about the activation of Nox 5 at the vascular level. 


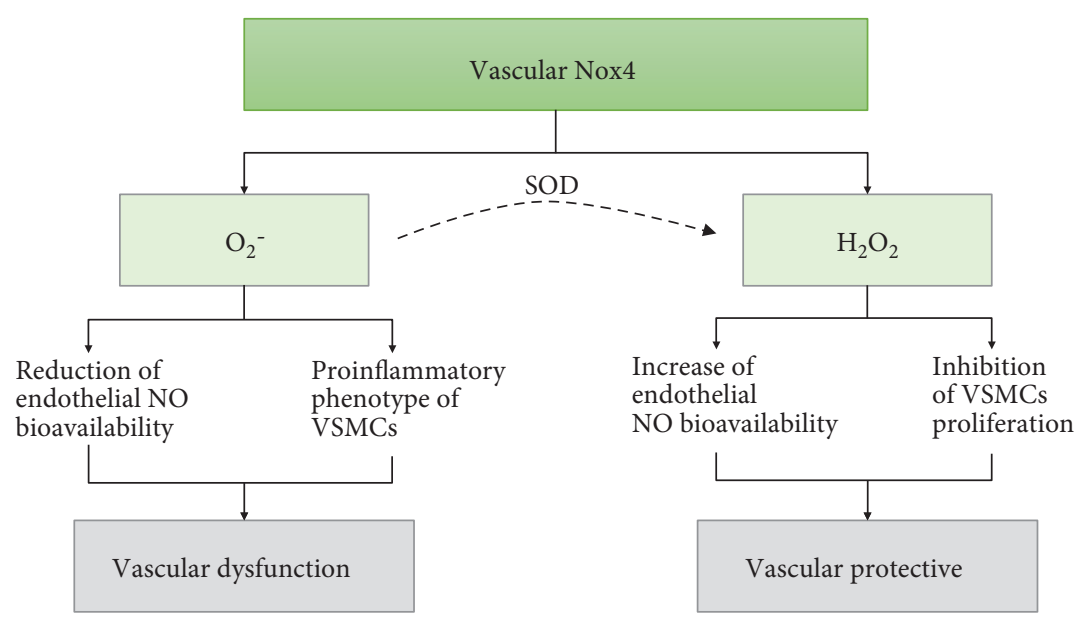

Figure 2: The Nox 4 paradox. Vascular Nox 4 generates superoxide anion $\left(\mathrm{O}_{2}{ }^{-}\right)$and hydrogen peroxide $\left(\mathrm{H}_{2} \mathrm{O}_{2}\right)$. Depending on which via predominates, Nox 4 activation can be damaging or protective. VSCMs: vascular smooth muscle cells.

On the contrary, Nox 4 is the most abundant isoform in the vascular system, and NADPH oxidase activity depends mainly on its expression under resting conditions [96, 97]. Nox 4 releases hydrogen peroxide $\left(\mathrm{H}_{2} \mathrm{O}_{2}\right)$ in preference to $\mathrm{O}_{2}{ }^{-}$[98], which can offer a protective role against atherogenesis, as $\mathrm{H}_{2} \mathrm{O}_{2}$ does not interact with $\mathrm{NO}$ to form $\mathrm{ONOO}^{-}$ [99-104]. Moreover, $\mathrm{H}_{2} \mathrm{O}_{2}$ activates eNOS [98, 105] and inhibits vascular smooth muscle cell proliferation, thereby preventing vascular inflammation and remodelling [100, 106]. However, other studies have demonstrated a detrimental role of Nox 4. For instance, Lozhkin et al. observed an increase in the expression and activity of Nox 4 during aging, which enhanced cellular and mitochondrial oxidative stress and vascular dysfunction, leading to a proinflammatory phenotype in VSMC [107]. Similarly, in experimental models of ischemic stroke [108, 109], cardiac hypertrophy [110], or diabetic cardiomyopathy [111], the role of Nox 4 is not beneficial. Figure 2 shows the paradoxical effects of vascular Nox 4.

One study using iron oxide nanoparticles $\left(\mathrm{Fe}_{2} \mathrm{O}_{3}-\mathrm{NPs}\right)$ demonstrated that, due to overexpression of Nox 4, $\mathrm{Fe}_{2} \mathrm{O}_{3}$ NPs disturbed the balance between oxidants and antioxidants, resulting in oxidative myocardial damage [112]. Other nanoparticles have shown effects on NADPH oxidases; for example, Sun et al. [113] demonstrated that AgNPs decreased cell viability, induced ROS generation, and led to early apoptosis in human umbilical vein endothelial cells through upregulation of Nox 4 protein expression. Abe et al. [114] and Kim et al. [115] described the properties of platinum-loaded tungsten oxide $\left(\mathrm{WO}_{3}-\mathrm{Pt}\right)$ nanoparticles and their interaction with organophosphorous compounds [116]. NADPH contains phosphorous, which is an excellent substrate for $\mathrm{WO}_{3}$ - Pt nanoparticles, and has recently been proposed as a NADPH oxidase biomimetic with potential as an antitumor agent [117].

The role of Nox 4 in vascular function continues to be a subject of controversy; some studies report a protective role against atherogenesis, while others show the contrary. Further research is needed to understand better the effect of nanoparticles targeted to Nox in the vascular system.
3.2. Uncoupled eNOS. NO is synthesized from L-arginine by the action of NOS [118]. There are three isoforms of NOS: endothelial (eNOS), neural (nNOS), and inducible (iNOS) [119]. The third of these is activated under inflammation, and the amount of NO it produces is greater than that generated by the other two isoforms [120]. eNOS converts $\mathrm{L}$-arginine into L-citrulline and $\mathrm{NO}$ in the presence of cofactors such as nicotinamide adenine dinucleotide phosphate (NADPH), $\mathrm{Ca}^{2+} /$ calmodulin (CaM), flavin adenine dinucleotide (FAD), flavin mononucleotide (FMN), and tetrahydrobiopterin (BH4) [121]. NO activates soluble guanylate cyclase (sGC), which stimulates the conversion of guanosine-5-triphosphate (GTP) to guanosine $3^{\prime}, 5^{\prime}$ cyclic monophosphate (cGMP), leading to a reduction of cytosolic calcium and vasodilation [122]. Decreased bioavailability of $\mathrm{NO}$ is the main cause of endothelial dysfunction. Vascular oxidative stress can contribute to the uncoupling of eNOS $[123,124]$ and, therefore, endothelial dysfunction. Uncoupled eNOS exhibits NADPH oxidase activity and produces $\mathrm{O}_{2}{ }^{-}$. The main causes of this uncoupling are deficiency of L-arginine, $\mathrm{BH}_{4}$, or eNOS S-glutathionation [123, 125]. Deficiency of $\mathrm{L}$-arginine can be related to an increase in arginase activity in blood vessels [126-128], and deficiency of $\mathrm{BH}_{4}$ is due to an increase in its oxidation [129]. eNOS can also be uncoupled by S-glutathionylation, observed in patients with hypertension, and increased levels of AT II [130]. In this respect, oxidative stress contributes to endothelial dysfunction: firstly, because $\mathrm{NO}$ is inactivated by $\mathrm{O}_{2}^{-}$to form $\mathrm{ONOO}^{-}$, and secondly, because persistent oxidative stress causes eNOS to uncouple (Figure 3).

Regarding the effects of nanoparticles on NOS, RamirezLee et al. [131] evaluated the effect of AgNPs using isolated perfused hearts from hypertensive rats. They reported that NO derived from both eNOS and iNOS was reduced, leading to increased vasoconstriction and myocardial contractility. Although the reduction of NO from iNOS could be considered beneficial due to its anti-inflammatory effect, the authors concluded that AgNPs intensify the hypertension. As we have discussed above, NO maintains vascular homeostasis, increases vascular endothelial growth factor, 


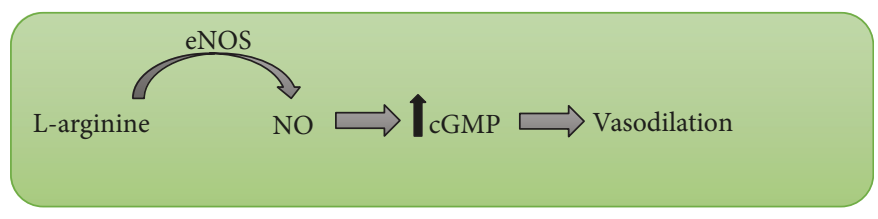

(a) Healthy endothelium

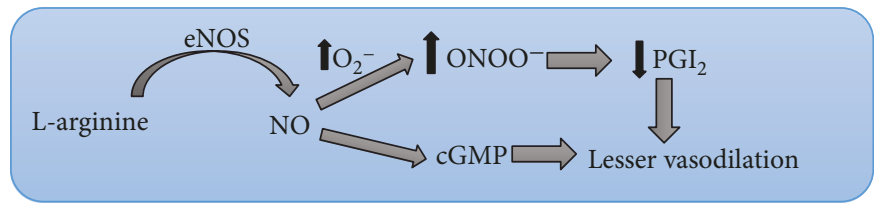

(b) Acute oxidative stress

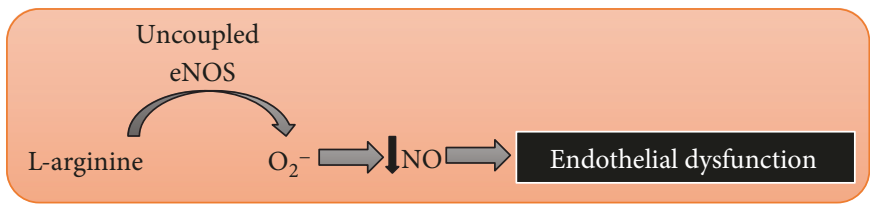

(c) Persistent oxidative stress

Figure 3: Endothelial dysfunction due to oxidative stress. The image shows how vascular oxidative stress leads to endothelial dysfunction. (a) represents the production of nitric oxide (NO) from L-arginine by endothelial nitric oxide synthase (eNOS) in a healthy endothelium, where levels of superoxide anion $\left(\mathrm{O}_{2}{ }^{-}\right)$are low. NO diffuses from the endothelium to the vascular smooth muscle, where it activates soluble guanylate cyclase (sGC), which increases the levels of guanosine $3^{\prime}, 5^{\prime}$ cyclic monophosphate (cGMP), thus leading to vasodilation. (b) represents acute vascular oxidative stress, with an increase in $\mathrm{O}_{2}^{-}$production, followed by an increase in peroxynitrite $\left(\mathrm{ONOO}^{-}\right)$ levels. $\mathrm{ONOO}^{-}$produces endothelial dysfunction by directly reducing the $\mathrm{NO}$ available for activating sGC and by reducing prostaglandin $\mathrm{I}_{2}\left(\mathrm{PGI}_{2}\right)$ content via nitration $\mathrm{PGI}_{2}$ synthase. If oxidative stress is persistent (c), eNOS becomes uncoupled, producing $\mathrm{O}_{2}{ }^{-}$instead of $\mathrm{NO}^{-}$ and aggravating endothelial dysfunction.

and prevents platelet adherence and leukocyte chemotaxis. Due to these effects, it is used to promote physiological angiogenesis in the treatment of peripheral arterial diseases. However, the ischemic event during peripheral ischemia produces $\mathrm{O}_{2}{ }^{-}$and diminishes the bioavailability of $\mathrm{NO}$ by forming $\mathrm{ONOO}^{-}$. An interesting recent study [132] developed a hybrid molecule consisting of a copolymer poly (lactic-co-glycolic acid) (PLGA) nanoparticle loaded with SA-2 and which contains both antioxidant and NO donor functionalities and provides a sufficiently therapeutic level of NO to treat peripheral arterial diseases.

3.3. Xanthine Oxidase in the Vascular Wall and Angiotensin II. Xanthine oxidase forms $\mathrm{O}_{2}{ }^{-}$and $\mathrm{H}_{2} \mathrm{O}_{2}$ [133-136]. Experimental studies have demonstrated that its expression is increased in response to AT II [83], and chronic activation of the renin-angiotensin system (RAS) may contribute to vascular xanthine oxidase activation [86]. The activation of AT II receptor 1 (AT1R), the high affinity receptor for AT II [137], also induces upregulation of NADPH oxidase activity, increasing $\mathrm{O}_{2}^{-}[85,138]$, which scavenges $\mathrm{NO}$ to form $\mathrm{ONOO}^{-}$and consequently diminishes NO bioavailability, leading to endothelial dysfunction. On the contrary, AT II receptor 2 (AT2R), located in the endothelium, enhances phosphorylation of eNOS, thereby increasing its activity [139]. In this way, AT2 $\mathrm{R}$ regulates $\mathrm{O}_{2}{ }^{-}$production in the opposite manner to AT1R $[139,140]$ and balances the prooxidative function of AT1R (Figure 4). Therefore, patients with chronic hypertension and activated RAS could benefit from nanoparticles that are capable of downregulating AT1R or upregulating AT2R, though as far as we know, no studies have investigated this so far. Nevertheless, some researchers have designed nanoparticles carrying AT II; for instance, Hennig et al. demonstrated that AT II-coupled nanoparticles can be used to establish high affinities to cells with an overexpression of AT1R [141].

The best characterized antihypertensive peptidesachieved by inhibiting angiotensin-converting enzyme (ACE) - are Ile-Pro-Pro (IPP) and Val-Pro-Pro (VPP). However, they are compromised by their low oral bioavailability, which is mainly due to their gastrointestinal degradation. Consequently, the use of nanoparticles as carrier systems encapsulating these peptides could prevent their proteolysis and enhance their systemic uptake. Yu et al. [142] tested poly-(lactic-co-glycolic) acid (PLGA) nanoparticles (PLGANPs) as an oral delivery system for antihypertensive small peptides in a model of spontaneously hypertensive rats. The authors concluded that PLGANP was a potential therapeutic treatment for hypertension.

3.4. Effect of NO on Mitochondrial Respiratory Chain Enzymes. Mitochondria are the main source of $\mathrm{O}_{2}{ }^{-}$[143]. NO binds to cytochrome oxidase (COX) and inhibits electron transfer to $\mathrm{O}_{2}$ [144]. The enzymes of the electron transfer chain show varying sensitivity to NO [145]. If exposure to $\mathrm{NO}$ is prolonged, the activity of NADH dehydrogenase is inhibited at mitochondrial complex I [146]. NO reacts with ubiquinol, oxidizing it to the respective semiquinone, which forms $\mathrm{O}_{2}{ }^{-}$by autoxidation to ubiquinone. $\mathrm{O}_{2}{ }^{-}$reacts with $\mathrm{NO}$ and forms $\mathrm{ONOO}^{-} \cdot \mathrm{O}_{2}^{-}$can also dismute to $\mathrm{H}_{2} \mathrm{O}_{2}$ 


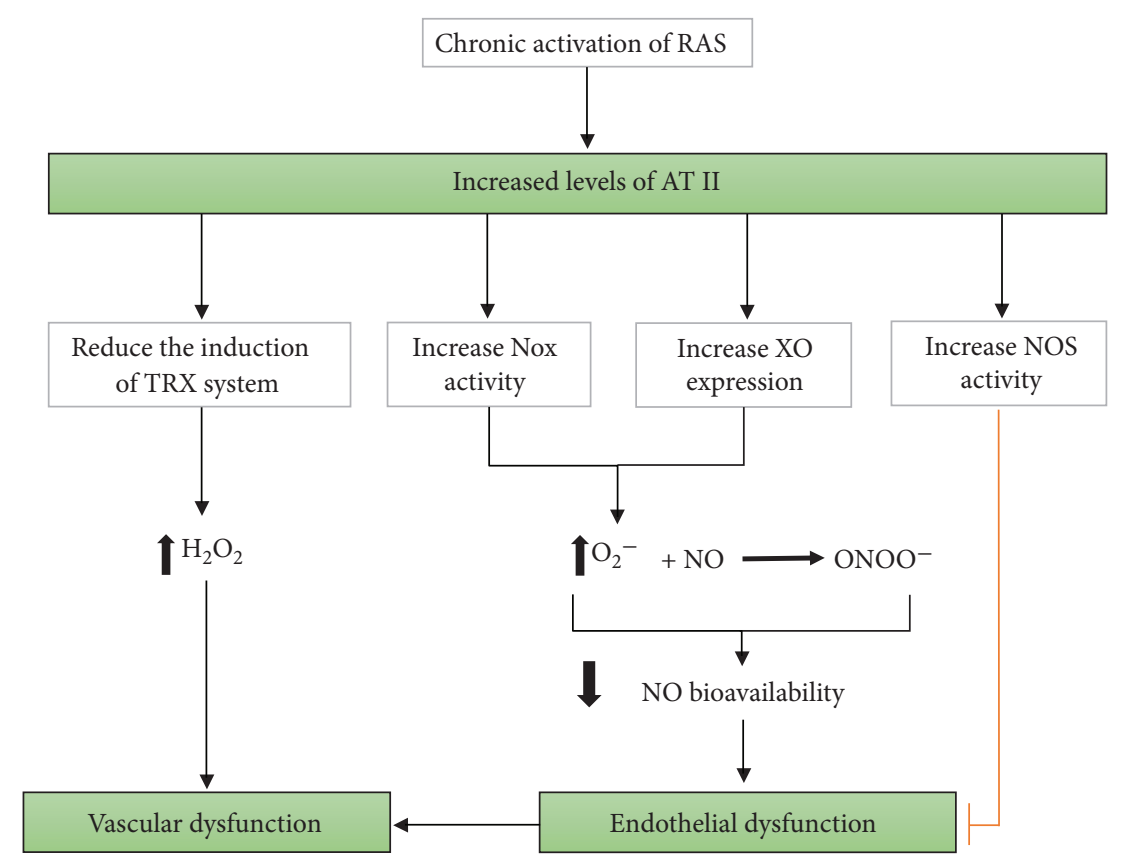

FIGURE 4: Chronic activation of the renin-angiotensin system (RAS) contributes to oxidative stress and vascular dysfunction. Increased levels of angiotensin II (AT II) lead to endothelial dysfunction through AT II receptor 1 (AT1R) activation, which in turn induces vascular oxidative stress by increasing NADPH oxidase (Nox) activity and xanthine oxidase (XO) expression. Both enzymes produce superoxide anion $\left(\mathrm{O}_{2}{ }^{-}\right)$, which scavenges nitric oxide (NO) by forming peroxynitrite $\left(\mathrm{ONOO}^{-}\right)$, consequently decreasing $\mathrm{NO}$ bioavailability and causing endothelial dysfunction. Moreover, AT II can undermine the induction of the antioxidant system thioredoxin (TRX), enhancing levels of $\mathrm{H}_{2} \mathrm{O}_{2}$ and contributing to vascular oxidative stress. $\mathrm{H}_{2} \mathrm{O}_{2}$ is the most stable and abundant ROS which, as a signalling messenger, maintains physiologic vascular homeostasis, but its overproduction is related to vascular dysfunction. In contrast, AT II receptor 2 (AT2R) activation can counteract the lesser NO bioavailability induced by vascular oxidative stress via eNOS phosphorylation, thereby increasing its activity.

catalyzed by MnSOD [147]. The main mitochondrial antioxidant defence is MnSOD, and dismutation of $\mathrm{O}_{2}^{-}$by this enzyme occurs at a lower magnitude to the formation of $\mathrm{ONOO}^{-}$. Consequently, $\mathrm{ONOO}^{-}$is elevated at high levels of NO. mtNOS is another NOS isoform present in the mitochondria [148, 149], but classic NOS isoforms are mainly responsible for cytosolic NO concentration. NO can spread to mitochondria, but at a very low concentration, for two reasons: first, because its concentration is low at physiological conditions; and second, because NO binds to cytosolic compounds. However, when iNOS is activated, as occurs during inflammation, levels of NO increase, as does the formation of $\mathrm{ONOO}^{-}$[150]. Therefore, NO plays an important role in the mitochondrial oxidative stress occurring in some pathological conditions, such as atherosclerosis [151]. Some nanoparticles, such as nanoceria, have demonstrated their ability to reduce the expression of iNOS, thus exerting anti-inflammatory effects $[67,152]$. Treatment of cultured cardiomyocytes with nanoceria has been shown to result in significant inhibition of cigarette smoke extract-induced ROS production [152].

3.5. Endothelial Dysfunction due to Oxidative Stress. The endothelium plays an essential role in vascular homeostasis and releases relaxing factors, such as NO, prostacyclin $\left(\mathrm{PGI}_{2}\right)$, or endothelium-derived hyperpolarizing factor (EDHF) [153]. Endothelial dysfunction is the first phase in the development of cardiovascular diseases. As already explained, the main cause of endothelial dysfunction is a decrease in NO bioavailability [154]. It is well known that oxidative stress contributes to endothelial dysfunction, as we have already described (see Figures 2 and 3). Excess of ROS generates $\mathrm{ONOO}^{-}$, which can reduce vasodilation by two mechanisms: first, by directly reducing the $\mathrm{NO}$ available for activating the cGC in the vascular smooth muscle, and second, by reducing prostaglandin $\mathrm{I}_{2}$ content via nitration $\mathrm{PGI}_{2}$ synthase [155]. Consequently, endothelial dysfunction represents an imbalance between vasodilator and vasoconstrictor agents released by the endothelium, reducing the capacity of vasodilation or increasing the response to vasoconstrictor agonists.

Recent evidence suggests that some kinds of nanoparticles, such as silica nanoparticles, affect vasodilator function depending on their charge and size [156]. Silica nanoparticles were shown to attenuate vasodilation in the aorta, which was partially restored using SOD [157], implicating oxidative stress as the mechanism responsible. In the same line, Guo et al. reported that silica nanoparticles induced endothelial dysfunction through mitochondrial dynamics and alteration of biogenesis [158]. However, on the other hand, ceria nanoparticles seem to restore endothelial-dependent vasodilation. Minarchick et al. investigated the effects of nanoceria on vascular reactivity in a rat model of hypertension and concluded that they decreased the microvascular dysfunction and oxidative stress associated with hypertension [159]. Indeed, nanoceria can be considered a promising type of 


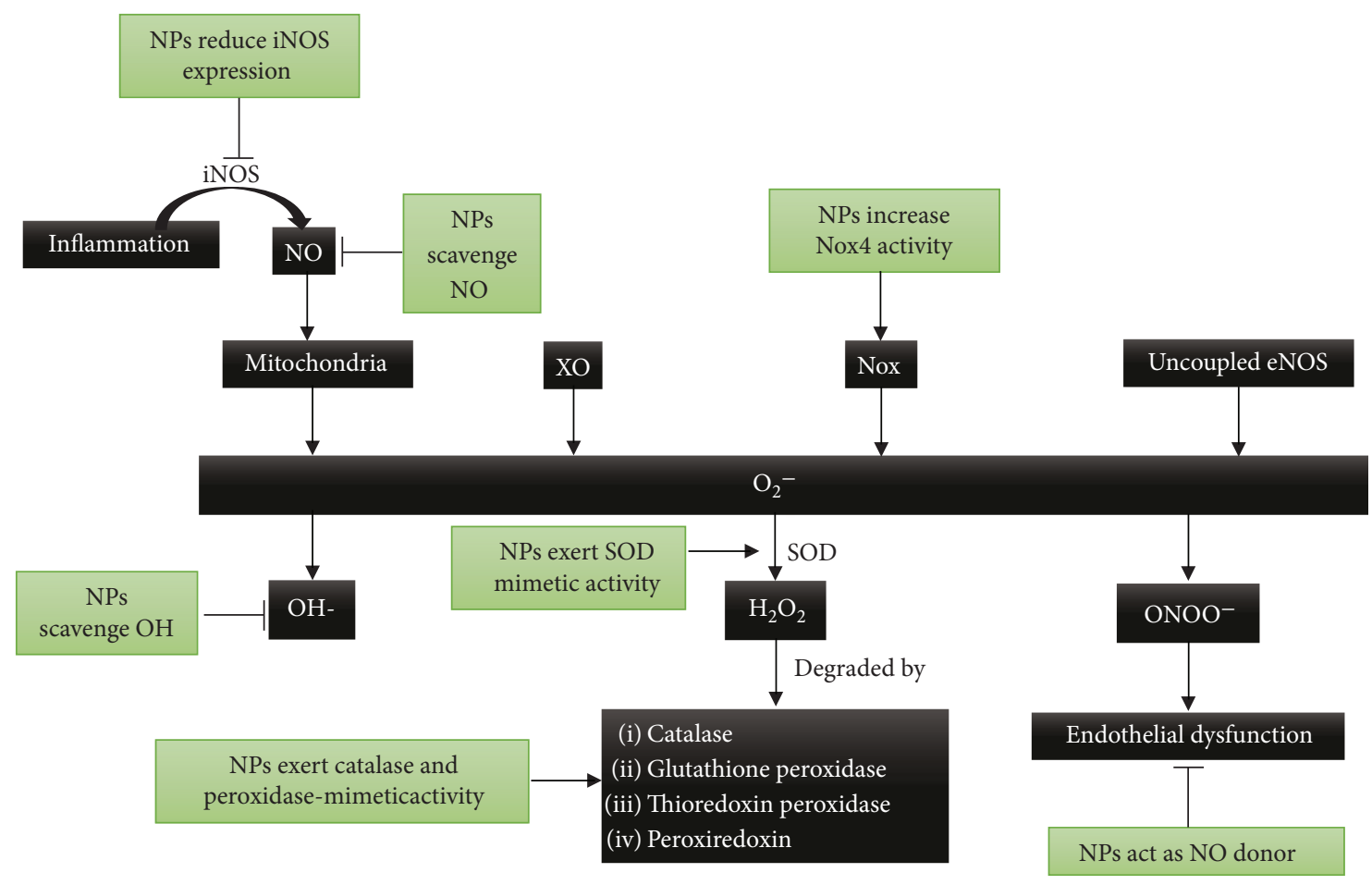

FIGURE 5: Effects of nanoparticles on the main mechanisms of vascular oxidative stress and antioxidant systems. Mitochondrial respiratory chain enzymes, xanthine oxidase (XO), NADPH oxidase (Nox), and uncoupled endothelial NO synthase (eNOS) are the main sources of superoxide anion $\left(\mathrm{O}_{2}{ }^{-}\right)$in the vascular wall. $\mathrm{O}_{2}{ }^{-}$can produce hydroxil radical $(\mathrm{OH})$, hydrogen peroxide $\left(\mathrm{H}_{2} \mathrm{O}_{2}\right)$, and peroxynitrite $\left(\mathrm{ONOO}^{-}\right)$. The enzymes that decompose $\mathrm{H}_{2} \mathrm{O}_{2}$ are catalase, glutathione, thioredoxin peroxidase, and peroxiredoxin. In inflammation, the induction of iNOS produces high levels of NO which react with mitochondrial respiratory chain enzymes and increase $\mathrm{O}_{2}{ }^{-}$production. Some nanoparticles (NPs), such as nanoceria, have demonstrated the ability to reduce the expression of iNOS. Moreover, nanoceria can scavenge both $\mathrm{NO}$ and $\mathrm{OH}$, thus proving to be anti-inflammatory and antioxidant agents. Some NPs increase Nox activity and can be used as antitumoral agents. The role of Nox 4 in vascular function is controversial; whereas some studies report a protective role against atherogenesis, others show the contrary. Certain NPs can be used as NO donors to reverse endothelial dysfunction. Some NPs exert SOD, catalase, oxidase, phosphatase, and peroxidase-mimetic activities.

nanoparticle. They contain a high density of $\mathrm{O}_{2}$ vacancy in their structure, which confers them the ability to store $\mathrm{O}_{2}$ during the lean phase and to return $\mathrm{O}_{2}$ to metal particles during the oxygen-rich phase. This mechanism is known as the $\mathrm{O}_{2}$ storage capacity of ceria [2]. $\mathrm{CeO}_{2} \mathrm{NPs}$ could have cardiovascular-protector effects that render them controllers of endothelial inflammation. In line with this, studies have demonstrated nanoceria are SOD mimetic in vitro [160] and antioxidant and anti-inflammatory effects in the murine myocardium [161]. In contrast, other studies have reported a decrease in vascular function after nanoceria incubation due to an increase in ROS generation $[162,163]$. It is likely that these contradictory effects are due to different basal levels of ROS in the animal models used.

Some studies have concluded that the effects of nanoparticles on endothelial function depend on the concentration and composition of the particles. $\mathrm{CeO}_{2} \mathrm{NPs}$ or nanoceria provoke a very slight inflammatory response in human aortic endothelial cells and seem to be rather benign in comparison with $\mathrm{Y}_{2} \mathrm{O}_{3}$ and $\mathrm{ZnO}$ nanoparticles $[164,165]$. In light of all the above, further investigations are needed to assess the role of different nanoparticles in vascular reactivity, endothelial dysfunction, and toxicity.
3.6. Vascular Antioxidant Systems. As we have previously indicated, SOD produces $\mathrm{H}_{2} \mathrm{O}_{2}$ as a result of the dismutation of $\mathrm{O}_{2}^{-}$. There are three isoforms of SOD: $\mathrm{Cu} / \mathrm{Zn}$ SOD or SOD1, located at cytoplasm and mitochondria intermembrane space; SOD2, expressed in the mitochondrial matrix; and SOD3, which is extracellular and largely expressed in the vascular wall [166]. Although the role of SOD is antioxidant, it is worth noting that the capacity of the downstream enzymes to degrade $\mathrm{H}_{2} \mathrm{O}_{2}$ influences the oxidative balance. In line with this, studies analysing the effect of SOD on atherogenesis have concluded that moderate levels of SOD reduce ROS and that elevated levels induce oxidative damage and increase levels of proaterogenic molecules [167-169].

The enzymes that decompose $\mathrm{H}_{2} \mathrm{O}_{2}$, the most stable and abundant ROS [170], are catalase, glutathione, and thioredoxin peroxidases, and the correct functioning of these systems is vital, since an excess of $\mathrm{H}_{2} \mathrm{O}_{2}$ can cause vascular injury. There is evidence of a dual role of ROS: on one hand, they are signalling messengers and maintain physiologic vascular homeostasis; on the other, ROS excess is related to vascular dysfunction, such as that which occurs in hypertension, atherosclerosis, diabetes, or acute coronary syndrome [171, 172]. Catalase is an important antioxidant enzyme located in peroxisomes [173], transforming $\mathrm{H}_{2} \mathrm{O}_{2}$ 
TABLE 1: Nanoparticles and their biological effects.

\begin{tabular}{|c|c|c|c|}
\hline References & Nanoparticle studied & Function & Cell type \\
\hline Manickam et al. [112] & Iron oxide nanoparticles & Oxidant by Nox 4 overexpression & Myocardium from mice \\
\hline Petty [117] & $\mathrm{WO}_{3}$-Pt nanoparticles & $\begin{array}{l}\text { Oxidant. NADPH oxidase } \\
\text { biomimetic }\end{array}$ & Tumor cells \\
\hline Sun et al. [113] & Silver nanoparticles & $\begin{array}{l}\text { Oxidant by increasing Nox } 4 \\
\text { expression }\end{array}$ & $\begin{array}{l}\text { Human umbilical vein endothelial } \\
\text { cells }\end{array}$ \\
\hline Ramirez-Lee et al. [131] & Silver nanoparticles & $\begin{array}{l}\text { Increase of hypertension due to a } \\
\text { decrease in NO levels }\end{array}$ & Myocardium from rats \\
\hline T. Yu et al. [142] & PLGA nanoparticles & Carrier. Treatment for hypertension & Hypertensive rats \\
\hline Le et al. [132] & PLGA nanoparticles & $\begin{array}{l}\text { ROS scavenger at vascular level and } \\
\text { endothelial protector }\end{array}$ & $\begin{array}{l}\text { Human umbilical vascular } \\
\text { endothelial cells }\end{array}$ \\
\hline Reddy and Labhasetwar [63] & PLGA nanoparticles & SOD carrier & $\begin{array}{l}\text { Rat focal cerebral ischemia/ } \\
\text { reperfusion injury }\end{array}$ \\
\hline Hennig et al. [141] & PEGylated quantum dots & Carrier of angiotensin II & AT1R-expressing cells \\
\hline C. Guo et al. [158] & Silica nanoparticles & $\begin{array}{l}\text { Endothelial injury induced by } \\
\text { mitochondrial dysfunction }\end{array}$ & Human endothelial cells \\
\hline Farooq et al. [157] & Silica nanoparticles & $\begin{array}{l}\text { Endothelial dysfunction induced by } \\
\text { oxidative stress }\end{array}$ & Aorta from rat \\
\hline D. Lee et al. [71] & PVAX & $\begin{array}{l}\text { Antioxidant, anti-inflammatory, } \\
\text { and antiapoptotic activity }\end{array}$ & $\begin{array}{l}\text { Hind-limb and liver from an } \\
\text { ischemia/reperfusion model in mice }\end{array}$ \\
\hline Marrache and Dhar [80] & $\begin{array}{l}\text { PLGA-b-PEG-TPP } \\
\text { nanoparticles }\end{array}$ & Nanocarriers & Mitochondria-acting therapeutics \\
\hline Marushima et al. [73] & RNP & $\begin{array}{l}\text { Neuroprotective agent due to its } \\
\text { ability to scavenge free radicals }\end{array}$ & $\begin{array}{c}\text { Middle cerebral artery from rats } \\
\text { with cerebral ischemia/reperfusion } \\
\text { injury }\end{array}$ \\
\hline $\begin{array}{l}\text { Chonpathompikunlert } \\
\text { et al. [74] }\end{array}$ & $\begin{array}{l}\text { Redox-polymer } \\
\text { nanotherapeutics }\end{array}$ & $\begin{array}{c}\text { Treatment of the neurodegenerative } \\
\text { diseases }\end{array}$ & Brain from SAMP8 mice \\
\hline Ciofani et al. [60] & Nanoceria & SOD and catalase mimetic & PC12 neuronal-like cells \\
\hline Estevez et al. [69] & Nanoceria & $\begin{array}{l}\text { Reduction of oxidative and } \\
\text { nitrosative damage after stroke }\end{array}$ & $\begin{array}{l}\text { Mouse hippocampal brain slice } \\
\text { model of ischemia }\end{array}$ \\
\hline Hirst et al. [67] & Nanoceria & $\begin{array}{l}\text { Anti-inflammatory and } \mathrm{NO} \\
\text { scavenger }\end{array}$ & Murine macrophages \\
\hline Niu et al. [152] & Nanoceria & Antioxidant & Cultured rat $\mathrm{H} 9 \mathrm{c} 2$ cardiomyocytes \\
\hline Niu et al. [161] & Nanoceria & Antioxidant and anti-inflammatory & Murine myocardium \\
\hline Gojova et al. [164] & Nanoceria & Inflammatory effect & Human aortic endothelial cells \\
\hline Wingard et al. [162] & Nanoceria & Vascular dysfunction & Aorta from mice \\
\hline Minarchick et al. [159] & Nanoceria & Vascular antioxidant & Arterioles from hypertensive rats \\
\hline Minarchick et al. [163] & Nanoceria & $\begin{array}{c}\text { Prooxidant. Microvascular } \\
\text { dysfunction }\end{array}$ & Arteriola from rats \\
\hline Kennedy et al. [165] & $\begin{array}{l}\text { Iron oxide, yttrium oxide, } \\
\text { cerium oxide, zinc oxide }\end{array}$ & Proinflammatory & Human vascular endothelial cell line \\
\hline Park et al. [187] & $\begin{array}{l}\text { Nanoparticles based on } \\
\text { polyoxalate }\end{array}$ & Antioxidant and anti-inflammatory & Doxorubicin-treated mice heart \\
\hline Seshadri et al. [189] & Polyketal particles & SOD carrier & Rat myocardium \\
\hline
\end{tabular}

$\mathrm{WO}_{3}$-Pt: platinum tungsten oxide; PLGA: copolymer poly (lactic-co-glycolic acid); SOD: superoxide dismutase; PEG: polyethylene glycol; PVAX: copolyoxalate containing vanillyl alcohol (VA); RNP: radical-containing-nanoparticles.

into $\mathrm{O}_{2}$ and water and playing a central role against oxidative stress. Cerium nanoparticles exhibit CAT-mimetic activity, and this effect depends on their surface area, with the smallest ones proving to be the most active [174].

Glutathione peroxidases (GPx) are an enzyme family with peroxidase activity. GPx reduce $\mathrm{H}_{2} \mathrm{O}_{2}$ and lipid hydroperoxides to water and their corresponding alcohols, where reduced glutathione (GSH) is the main electron donor. GPx oxidizes GSH to form glutathione disulphide (GSSG), a reaction that is reversed by glutathione reductase, a NADPHdependent enzyme [175]. This enzyme family protects against oxidative damage and represents the major antioxidant system within many cells [176]. The antioxidant property of glutathione lies in the presence of thiols, molecules that contain a sulfhydryl $(\mathrm{SH})$ side chain group. Thiols reduce RONS by accepting their unpaired electron, which is 
essential for maintaining cellular reduction-oxidation (redox) status in favour of the former. There are several isoforms; GPx1, the most abundant in mitochondria and cytoplasm, is expressed in red blood cells, and its low activity has been related to cardiovascular risk [177].

The thioredoxin (TRX) system is integrated by NADPH, thioredoxin reductase, and thioredoxin, and its function is to regulate the equilibrium between protein dithiol and disulphide through disulphide reductase activity. The TRX system provides electrons to peroxiredoxins (thioldependent peroxidases) in order to remove RONS [178], and the reduced TRX peroxidase can scavenge $\mathrm{H}_{2} \mathrm{O}_{2}$ [179]. Regarding the TRX system's role in vascular function, both endothelial and smooth muscle cells express TRX, but the regulatory mechanism involved in its expression seems to differ. In the endothelium, it appears that TRX is a ROSinducible protein, since treatment with $\mathrm{H}_{2} \mathrm{O}_{2}$ increases its expression [180, 181], whereas, in vascular smooth muscle cells, TRX is related to cell proliferation, and its induction is not regulated by ROS [180]. Treatment with AT II reduces the induction of TRX, contributing to oxidative stress in hypertension [87]. Moreover, TRX increases in response to an excess of NO due to activation of iNOS, representing a mechanism against vascular inflammation, nitrosative stress, and atherosclerosis [182].

Peroxiredoxins are a family of proteins that regulate levels of $\mathrm{H}_{2} \mathrm{O}_{2}$ by using TRX as an electron donor, and their function depends on the reduced forms of TRX and glutathione [183]. The peroxiredoxin 4 is capable of scavenging intracellular ROS from the endoplasmic reticulum, and oxidative stress and endoplasmic reticulum stress have been demonstrated to contribute to the onset and development of the inflammation that accompanies vascular disease, such as atherosclerosis $[184,185]$. Another family with atheroprotective properties and anti-inflammatory effects-exerted by degrading $\mathrm{H}_{2} \mathrm{O}_{2}$-is the paraoxonase (PON) family, which is composed of three members: PON1, PON2, and PON3. PON2 and PON3 are expressed in the vascular wall. PONs also neutralize homocysteine thiolactatone, which has been related to vascular damage and atherogenesis [186].

Due to the abovementioned aspects, targeting the overproduction of $\mathrm{H}_{2} \mathrm{O}_{2}$ with nanoparticles could have beneficial effects on oxidative stress in cardiovascular diseases. In this regard, nanoparticles based on polyoxalate have been demonstrated to limit the effects of $\mathrm{H}_{2} \mathrm{O}_{2}$ on ischemia/ reperfusion injury and have shown antioxidative and anti-inflammatory effects [187]. The use of nanoparticles as carriers has been championed widely [188]. In line with this, researchers have designed SOD1-carrying nanoparticles that have been shown to improve postmyocardial infarction cardiac function [189]. Although the role of nanoparticles as carriers is of undoubtable interest, this subject goes beyond the scope of the present review. Other reviews describe the main characteristics of nanocarriers with respect to the design new drug delivery systems [188, 190]. Some nanomaterials, such as nanoceria, have multienzyme mimetic activities. These nanoparticles are able to mimic SOD, catalase, oxidase, phosphatase, and peroxidase. Moreover, nanoceria can scavenge hydroxyl radicals and nitric oxide radicals [191]. In light of all of this, cerium nanoparticles exhibit great potential to treat diseases related to oxidative stress, as the majority of nanomaterials scavenge only a single type of RONS. In addition, nanoceria could have an anti-inflammatory effect due to their ability to scavenge NO. Figure 5 shows the main mechanisms of vascular oxidative stress and antioxidant systems and the effects of nanoparticles on them. Table 1 summarizes the different types of nanoparticles and their effects.

\section{Conclusion}

The aim of the present review is to analyse the effects of nanoparticles on oxidative stress in the vascular system. The elevated levels of RONS in the vascular wall are related to cardiovascular disease and a decreased bioavailability of $\mathrm{NO}$, which leads to endothelial dysfunction. Some nanoparticles are antioxidants and may improve the vascular dysfunction associated with hypertension, diabetes mellitus, or atherosclerosis. However, other nanoparticles have displayed toxicity, as well as proinflammatory and prooxidant effects in endothelial cells. This toxicity seems to depend on the type and size of the nanoparticle in question. Nanoceria are one of the most promising types of nanoparticles in terms of restoring the oxidative balance and endothelial function. However, very few studies have focused on the effects of nanoceria on vascular reactivity, and so further research is needed in order to clarify the mechanism of these nanoparticles when interacting with the vascular system. We can conclude that, even though nanoparticles have extensive potential therapeutic applications in medicine, more toxicity studies are vital to acquire a greater understanding of this fascinating and promising technology.

\section{Conflicts of Interest}

No potential conflicts of interest relevant to this article were reported.

\section{Authors' Contributions}

M. D. Mauricio and S. Guerra-Ojeda contributed equally to this work and share first authorship.

\section{Acknowledgments}

The authors thank Brian Normanly (University of ValenciaCIBERehd) for his editorial assistance. This study was financed by grants PI16/1083, PI16/0301, and CIBERehd CB06/04/0071 by Instituto de Salud Carlos III and by the European Regional Development Fund (ERDF "A way to build Europe"). IE-L is a recipient of a predoctoral contract from FISABIO (UGP-15-144). MR and VMV are recipients of contracts from the Ministry of Health of the Valencian Regional Government and Carlos III Health Institute (CPII16/00037 and CES10/030, respectively) and PROMETEOII 2014/035 from the Regional Ministry Education of Valencian Community. 


\section{References}

[1] G. Bao, S. Mitragotri, and S. Tong, "Multifunctional nanoparticles for drug delivery and molecular imaging," Annual Review of Biomedical Engineering, vol. 15, no. 1, pp. 253282, 2013.

[2] I. Celardo, J. Z. Pedersen, E. Traversa, and L. Ghibelli, "Pharmacological potential of cerium oxide nanoparticles," Nanoscale, vol. 3, no. 4, pp. 1411-1420, 2011.

[3] W. H. De Jong and P. J. Borm, "Drug delivery and nanoparticles: applications and hazards," International Journal of Nanomedicine, vol. 3, no. 2, pp. 133-149, 2008.

[4] P. J. Borm, D. Robbins, S. Haubold et al., "The potential risks of nanomaterials: a review carried out for ECETOC," Particle and Fibre Toxicology, vol. 3, no. 1, p. 11, 2006.

[5] P. A. Stapleton and T. R. Nurkiewicz, "Vascular distribution of nanomaterials," Wiley Interdisciplinary Reviews. Nanomedicine and Nanobiotechnology, vol. 6, no. 4, pp. 338-348, 2014.

[6] A. J. Kattoor, N. V. K. Pothineni, D. Palagiri, and J. L. Mehta, "Oxidative stress in atherosclerosis," Current Atherosclerosis Reports, vol. 19, no. 11, p. 42, 2017.

[7] A. K. Singh, "Chapter 1-introduction to nanoparticles and nanotoxicology," in Engineered Nanoparticles, pp. 1-18, Academic Press, Boston, 2016.

[8] R. Ghosh Chaudhuri and S. Paria, "Core/shell nanoparticles: classes, properties, synthesis mechanisms, characterization, and applications," Chemical Reviews, vol. 112, no. 4, pp. 2373-2433, 2012.

[9] B. D. Chithrani and W. C. W. Chan, "Elucidating the mechanism of cellular uptake and removal of protein-coated gold nanoparticles of different sizes and shapes," Nano Letters, vol. 7, no. 6, pp. 1542-1550, 2007.

[10] V. De Matteis and R. Rinaldi, "Toxicity assessment in the nanoparticle era," in Cellular and Molecular Toxicology of Nanoparticles, Q. Saquib, M. Faisal, A. A. Al-Khedhairy, and A. A. Alatar, Eds., pp. 1-19, Springer International Publishing, Cham, 2018.

[11] Y. Panahi, M. Farshbaf, M. Mohammadhosseini et al., "Recent advances on liposomal nanoparticles: synthesis, characterization and biomedical applications," Artificial Cells, Nanomedicine, and Biotechnology, vol. 45, no. 4, pp. 788-799, 2017.

[12] M. R. Mozafari, "Liposomes: an overview of manufacturing techniques," Cellular \& Molecular Biology Letters, vol. 10, no. 4, pp. 711-719, 2005.

[13] Y. Malam, M. Loizidou, and A. M. Seifalian, "Liposomes and nanoparticles: nanosized vehicles for drug delivery in cancer," Trends in Pharmacological Sciences, vol. 30, no. 11, pp. 592-599, 2009.

[14] K. M. El-Say and H. S. El-Sawy, "Polymeric nanoparticles: promising platform for drug delivery," International Journal of Pharmaceutics, vol. 528, no. 1-2, pp. 675-691, 2017.

[15] O. C. Farokhzad and R. Langer, "Impact of nanotechnology on drug delivery," ACS Nano, vol. 3, no. 1, pp. 16-20, 2009.

[16] T. Patel, J. Zhou, J. M. Piepmeier, and W. M. Saltzman, "Polymeric nanoparticles for drug delivery to the central nervous system," Advanced Drug Delivery Reviews, vol. 64, no. 7, pp. 701-705, 2012.

[17] C. I. C. Crucho and M. T. Barros, "Polymeric nanoparticles: a study on the preparation variables and characterization methods," Materials Science \& Engineering. C, Materials for Biological Applications, vol. 80, pp. 771-784, 2017.

[18] C. R. Patra, R. Bhattacharya, D. Mukhopadhyay, and P. Mukherjee, "Fabrication of gold nanoparticles for targeted therapy in pancreatic cancer," Advanced Drug Delivery Reviews, vol. 62, no. 3, pp. 346-361, 2010.

[19] P. C. Chen, S. C. Mwakwari, and A. K. Oyelere, "Gold nanoparticles: from nanomedicine to nanosensing," Nanotechnology, Science and Applications, vol. Volume 1, pp. 45-66, 2008.

[20] A. P. Alivisatos, K. P. Johnsson, X. Peng et al., "Organization of 'nanocrystal molecules' using DNA," Nature, vol. 382, no. 6592, pp. 609-611, 1996.

[21] I. H. El-Sayed, X. Huang, and M. A. El-Sayed, "Surface plasmon resonance scattering and absorption of anti-EGFR antibody conjugated gold nanoparticles in cancer diagnostics: applications in oral cancer," Nano Letters, vol. 5, no. 5, pp. 829-834, 2005.

[22] H. Gao, W. Shi, and L. B. Freund, "From the cover: mechanics of receptor-mediated endocytosis," Proceedings of the National Academy of Sciences of the United States of America, vol. 102, no. 27, pp. 9469-9474, 2005.

[23] S. Andreescu, M. Ornatska, J. S. Erlichman, A. Estevez, and J. C. Leiter, "Biomedical applications of metal oxide nanoparticles," in Fine Particles in Medicine and Pharmacy, pp. 57100, Springer, Boston, MA, 2012.

[24] W. Tu, Y. Dong, J. Lei, and H. Ju, "Low-potential photoelectrochemical biosensing using porphyrin-functionalized $\mathrm{TiO}_{2}$ nanoparticles," Analytical Chemistry, vol. 82, no. 20, pp. 8711-8716, 2010.

[25] Y. Wang, Q. Zhao, N. Han et al., "Mesoporous silica nanoparticles in drug delivery and biomedical applications," Nanomedicine: Nanotechnology, Biology and Medicine, vol. 11, no. 2, pp. 313-327, 2015.

[26] Z.-Y. Zhang, Y. D. Xu, Y. Y. Ma et al., “Biodegradable ZnO@polymer core-shell nanocarriers: $\mathrm{pH}$-triggered release of doxorubicin in vitro," Angewandte Chemie International Edition, vol. 52, no. 15, pp. 4127-4131, 2013.

[27] D. Singh, P. Dubey, M. Pradhan, and M. R. Singh, "Ceramic nanocarriers: versatile nanosystem for protein and peptide delivery," Expert Opinion on Drug Delivery, vol. 10, no. 2, pp. 241-259, 2013.

[28] D. Singh, S. Singh, J. Sahu, S. Srivastava, and M. R. Singh, "Ceramic nanoparticles: recompense, cellular uptake and toxicity concerns," Artificial Cells, Nanomedicine, and Biotechnology, vol. 44, no. 1, pp. 401-409, 2014.

[29] C. Xu, Y. Lin, J. Wang et al., "Nanoceria-triggered synergetic drug release based on $\mathrm{CeO}_{2}$-capped mesoporous silica hostguest interactions and switchable enzymatic activity and cellular effects of $\mathrm{CeO}_{2}$," Advanced Healthcare Materials, vol. 2, no. 12, pp. 1591-1599, 2013.

[30] M. Dziadek, E. Stodolak-Zych, and K. Cholewa-Kowalska, "Biodegradable ceramic-polymer composites for biomedical applications: a review," Materials Science \& Engineering: $C$, vol. 71, pp. 1175-1191, 2017.

[31] S. Ghaderi, B. Ramesh, and A. M. Seifalian, "Fluorescence nanoparticles 'quantum dots' as drug delivery system and their toxicity: a review," Journal of Drug Targeting, vol. 19, no. 7, pp. 475-486, 2011.

[32] Y. Xing, Z. Xia, and J. Rao, "Semiconductor quantum dots for biosensing and in vivo imaging," IEEE Transactions on Nanobioscience, vol. 8, no. 1, pp. 4-12, 2009. 
[33] Y. C. Cao, R. Jin, and C. A. Mirkin, "Nanoparticles with Raman spectroscopic fingerprints for DNA and RNA detection," Science, vol. 297, no. 5586, pp. 1536-1540, 2002.

[34] S.-Y. Lin, N. T. Chen, S. P. Sun et al., "The protease-mediated nucleus shuttles of subnanometer gold quantum dots for real-time monitoring of apoptotic cell death," Journal of the American Chemical Society, vol. 132, no. 24, pp. 8309-8315, 2010.

[35] C. Cha, S. R. Shin, N. Annabi, M. R. Dokmeci, and A. Khademhosseini, "Carbon-based nanomaterials: multifunctional materials for biomedical engineering," ACS Nano, vol. 7, no. 4, pp. 2891-2897, 2013.

[36] S. Maleki Dizaj, A. Mennati, S. Jafari, K. Khezri, and K. Adibkia, "Antimicrobial activity of carbon-based nanoparticles," Advanced Pharmaceutical Bulletin, vol. 5, no. 1, pp. 19-23, 2015.

[37] M. L. Miglietta, G. Rametta, and G. di Francia, "Characterization of carbon based nanoparticles dispersion in aqueous solution using dynamic light scattering technique," Macromolecular Symposia, vol. 286, no. 1, pp. 95-100, 2009.

[38] M. Patra, X. Ma, C. Isaacson et al., "Changes in agglomeration of fullerenes during ingestion and excretion in Thamnocephalus platyurus," Environmental Toxicology and Chemistry, vol. 30, no. 4, pp. 828-835, 2011.

[39] S. Vardharajula, S. Z. Ali, P. M. Tiwari et al., "Functionalized carbon nanotubes: biomedical applications," International Journal of Nanomedicine, vol. 7, pp. 5361-5374, 2012.

[40] B. S. Harrison and A. Atala, "Carbon nanotube applications for tissue engineering," Biomaterials, vol. 28, no. 2, pp. 344353, 2007.

[41] P. Cherukuri, S. M. Bachilo, S. H. Litovsky, and R. B. Weisman, "Near-infrared fluorescence microscopy of single-walled carbon nanotubes in phagocytic cells," Journal of the American Chemical Society, vol. 126, no. 48, pp. 15638-15639, 2004.

[42] S.-T. Yang, J. Luo, Q. Zhou, and H. Wang, "Pharmacokinetics, metabolism and toxicity of carbon nanotubes for biomedical purposes," Theranostics, vol. 2, no. 3, pp. 271-282, 2012.

[43] C.-W. Lam, J. T. James, R. McCluskey, S. Arepalli, and R. L. Hunter, "A review of carbon nanotube toxicity and assessment of potential occupational and environmental health risks," Critical Reviews in Toxicology, vol. 36, no. 3, pp. 189-217, 2006.

[44] P. Wick, P. Manser, L. Limbach et al., "The degree and kind of agglomeration affect carbon nanotube cytotoxicity," Toxicology Letters, vol. 168, no. 2, pp. 121-131, 2007.

[45] Q. Mu, G. Jiang, L. Chen et al., "Chemical basis of interactions between engineered nanoparticles and biological systems," Chemical Reviews, vol. 114, no. 15, pp. 7740-7781, 2014.

[46] K. W. Powers, M. Palazuelos, B. M. Moudgil, and S. M. Roberts, "Characterization of the size, shape, and state of dispersion of nanoparticles for toxicological studies," Nanotoxicology, vol. 1, no. 1, pp. 42-51, 2007.

[47] H. Qiao, W. Liu, H. Gu, D. Wang, and Y. Wang, "The transport and deposition of nanoparticles in respiratory system by inhalation," Journal of Nanomaterials, vol. 2015, Article ID 394507, 8 pages, 2015.

[48] Y. Qiu, Y. Liu, L. Wang et al., "Surface chemistry and aspect ratio mediated cellular uptake of Au nanorods," Biomaterials, vol. 31, no. 30, pp. 7606-7619, 2010.
[49] H. Y. Nam, S. M. Kwon, H. Chung et al., "Cellular uptake mechanism and intracellular fate of hydrophobically modified glycol chitosan nanoparticles," Journal of Controlled Release, vol. 135, no. 3, pp. 259-267, 2009.

[50] E. Caballero-Díaz, C. Pfeiffer, L. Kastl et al., "The toxicity of silver nanoparticles depends on their uptake by cells and thus on their surface chemistry," Particle and Particle Systems Characterization, vol. 30, no. 12, pp. 1079-1085, 2013.

[51] A. M. El Badawy, R. G. Silva, B. Morris, K. G. Scheckel, M. T. Suidan, and T. M. Tolaymat, "Surface charge-dependent toxicity of silver nanoparticles," Environmental Science \& Technology, vol. 45, no. 1, pp. 283-287, 2011.

[52] R. Frick, B. Müller-Edenborn, A. Schlicker et al., "Comparison of manganese oxide nanoparticles and manganese sulfate with regard to oxidative stress, uptake and apoptosis in alveolar epithelial cells," Toxicology Letters, vol. 205, no. 2, pp. 163-172, 2011.

[53] M. Ahamed, M. S. AlSalhi, and M. K. J. Siddiqui, "Silver nanoparticle applications and human health," Clinica Chimica Acta, vol. 411, no. 23-24, pp. 1841-1848, 2010.

[54] J. P. M. Almeida, A. L. Chen, A. Foster, and R. Drezek, "In vivo biodistribution of nanoparticles," Nanomedicine, vol. 6, no. 5, pp. 815-835, 2011.

[55] H. H. Gustafson, D. Holt-Casper, D. W. Grainger, and H. Ghandehari, "Nanoparticle uptake: the phagocyte problem," Nano Today, vol. 10, no. 4, pp. 487-510, 2015.

[56] Z. Lin, N. A. Monteiro-Riviere, and J. E. Riviere, "Pharmacokinetics of metallic nanoparticles," Wiley Interdisciplinary Reviews. Nanomedicine and Nanobiotechnology, vol. 7, no. 2, pp. 189-217, 2015.

[57] A. M. Pisoschi and A. Pop, "The role of antioxidants in the chemistry of oxidative stress: a review," European Journal of Medicinal Chemistry, vol. 97, pp. 55-74, 2015.

[58] M. Goodman, R. M. Bostick, O. Kucuk, and D. P. Jones, "Clinical trials of antioxidants as cancer prevention agents: past, present, and future," Free Radical Biology \& Medicine, vol. 51, no. 5, pp. 1068-1084, 2011.

[59] A. Karakoti, S. Singh, J. M. Dowding, S. Seal, and W. T. Self, "Redox-active radical scavenging nanomaterials," Chemical Society Reviews, vol. 39, no. 11, pp. 4422-4432, 2010.

[60] G. Ciofani, G. G. Genchi, I. Liakos et al., "Effects of cerium oxide nanoparticles on PC12 neuronal-like cells: proliferation, differentiation, and dopamine secretion," Pharmaceutical Research, vol. 30, no. 8, pp. 2133-2145, 2013.

[61] B. J. Connell, M. C. Saleh, I. Kucukkaya, A. S. Abd-El-Aziz, B. V. Khan, and T. M. Saleh, "UPEI-300, a conjugate of lipoic acid and edaravone, mediates neuroprotection in ischemia/ reperfusion," Neuroscience Letters, vol. 561, pp. 151-155, 2014.

[62] M. Li, K. T. Al-Jamal, K. Kostarelos, and J. Reineke, "Physiologically based pharmacokinetic modeling of nanoparticles," ACS Nano, vol. 4, no. 11, pp. 6303-6317, 2010.

[63] M. K. Reddy and V. Labhasetwar, "Nanoparticle-mediated delivery of superoxide dismutase to the brain: an effective strategy to reduce ischemia-reperfusion injury," The FASEB Journal, vol. 23, no. 5, pp. 1384-1395, 2009.

[64] Y.-P. Chen, C. T. Chen, Y. Hung et al., "A new strategy for intracellular delivery of enzyme using mesoporous silica nanoparticles: superoxide dismutase," Journal of the American Chemical Society, vol. 135, no. 4, pp. 1516-1523, 2013. 
[65] M. Kajita, K. Hikosaka, M. Iitsuka, A. Kanayama, N. Toshima, and Y. Miyamoto, "Platinum nanoparticle is a useful scavenger of superoxide anion and hydrogen peroxide," Free Radical Research, vol. 41, no. 6, pp. 615-626, 2007.

[66] T. Pirmohamed, J. M. Dowding, S. Singh et al., "Nanoceria exhibit redox state-dependent catalase mimetic activity," Chemical Communications, vol. 46, no. 16, pp. 2736-2738, 2010.

[67] S. M. Hirst, A. S. Karakoti, R. D. Tyler, N. Sriranganathan, S. Seal, and C. M. Reilly, "Anti-inflammatory properties of cerium oxide nanoparticles," Small, vol. 5, no. 24, pp. 28482856, 2009.

[68] J. M. Dowding, S. Seal, and W. T. Self, "Cerium oxide nanoparticles accelerate the decay of peroxynitrite $\left(\mathrm{ONOO}^{-}\right)$," Drug Delivery and Translational Research, vol. 3, no. 4, pp. 375-379, 2013.

[69] A. Y. Estevez, S. Pritchard, K. Harper et al., "Neuroprotective mechanisms of cerium oxide nanoparticles in a mouse hippocampal brain slice model of ischemia," Free Radical Biology \& Medicine, vol. 51, no. 6, pp. 1155-1163, 2011.

[70] G. Oberdörster, E. Oberdörster, and J. Oberdörster, "Nanotoxicology: an emerging discipline evolving from studies of ultrafine particles," Environmental Health Perspectives, vol. 113, no. 7, pp. 823-839, 2005.

[71] D. Lee, S. Bae, D. Hong et al., " $\mathrm{H}_{2} \mathrm{O}_{2}$-responsive molecularly engineered polymer nanoparticles as ischemia/reperfusiontargeted nanotherapeutic agents," Scientific Reports, vol. 3, no. 1, p. 2233, 2013.

[72] S.-L. Wu, J.-C. Chen, C.-C. Li, H.-Y. Lo, T.-Y. Ho, and C.-Y. Hsiang, "Vanillin improves and prevents trinitrobenzene sulfonic acid-induced colitis in mice," The Journal of Pharmacology and Experimental Therapeutics, vol. 330, no. 2, pp. 370-376, 2009.

[73] A. Marushima, K. Suzuki, Y. Nagasaki et al., "Newly synthesized radical-containing nanoparticles enhance neuroprotection after cerebral ischemia-reperfusion injury," Neurosurgery, vol. 68, no. 5, pp. 1418-1426, 2011.

[74] P. Chonpathompikunlert, T. Yoshitomi, L. B. Vong, N. Imaizumi, Y. Ozaki, and Y. Nagasaki, "Recovery of cognitive dysfunction via orally administered redox-polymer nanotherapeutics in SAMP8 mice," PloS One, vol. 10, no. 5, article e0126013, 2015.

[75] R. Martín, C. Menchón, N. Apostolova et al., "Nano-jewels in biology. Gold and platinum on diamond nanoparticles as antioxidant systems against cellular oxidative stress," ACS Nano, vol. 4, no. 11, pp. 6957-6965, 2010.

[76] Y. Li, X. He, J. J. Yin et al., "Acquired superoxide-scavenging ability of ceria nanoparticles," Angewandte Chemie (International Ed. in English), vol. 54, no. 6, pp. 1832-1835, 2015.

[77] S. R. Pieczenik and J. Neustadt, "Mitochondrial dysfunction and molecular pathways of disease," Experimental and Molecular Pathology, vol. 83, no. 1, pp. 84-92, 2007.

[78] S. Rovira-Llopis, N. Apostolova, C. Bañuls, J. Muntané, M. Rocha, and V. M. Victor, "Mitochondria, the NLRP3 inflammasome, and sirtuins in type 2 diabetes: new therapeutic targets," Antioxidants \& Redox Signaling, vol. 29, no. 8, pp. 749-791, 2018.

[79] N. Apostolova and V. M. Victor, "Molecular strategies for targeting antioxidants to mitochondria: therapeutic implications," Antioxidants \& Redox Signaling, vol. 22, no. 8, pp. 686-729, 2015.
[80] S. Marrache and S. Dhar, "Engineering of blended nanoparticle platform for delivery of mitochondria-acting therapeutics," Proceedings of the National Academy of Sciences of the United States of America, vol. 109, no. 40, pp. 16288-16293, 2012.

[81] U. Förstermann, "Oxidative stress in vascular disease: causes, defense mechanisms and potential therapies," Nature Clinical Practice. Cardiovascular Medicine, vol. 5, no. 6, pp. 338-349, 2008.

[82] U. Förstermann, "Nitric oxide and oxidative stress in vascular disease," Pflügers Archiv, vol. 459, no. 6, pp. 923-939, 2010.

[83] U. Landmesser, S. Spiekermann, C. Preuss et al., “Angiotensin II induces endothelial xanthine oxidase activation: role for endothelial dysfunction in patients with coronary disease," Arteriosclerosis, Thrombosis, and Vascular Biology, vol. 27, no. 4, pp. 943-948, 2007.

[84] U. Förstermann, N. Xia, and H. Li, "Roles of vascular oxidative stress and nitric oxide in the pathogenesis of atherosclerosis," Circulation Research, vol. 120, no. 4, pp. 713-735, 2017.

[85] A. Warnholtz, G. Nickenig, E. Schulz et al., "Increased $\mathrm{NADH}$-oxidase-mediated superoxide production in the early stages of atherosclerosis: evidence for involvement of the renin-angiotensin system," Circulation, vol. 99, no. 15, pp. 2027-2033, 1999.

[86] E. M. A. Mervaala, Z. J. Cheng, I. Tikkanen et al., "Endothelial dysfunction and xanthine oxidoreductase activity in rats with human renin and angiotensinogen genes," Hypertension, vol. 37, no. 2, pp. 414-418, 2001.

[87] M. Tanito, H. Nakamura, Y. W. Kwon et al., "Enhanced oxidative stress and impaired thioredoxin expression in spontaneously hypertensive rats," Antioxidants \& Redox Signaling, vol. 6, no. 1, pp. 89-97, 2004.

[88] H.-J. Hsieh, C.-A. Liu, B. Huang, A. H. H. Tseng, and D. Wang, "Shear-induced endothelial mechanotransduction: the interplay between reactive oxygen species (ROS) and nitric oxide (NO) and the pathophysiological implications," Journal of Biomedical Science, vol. 21, no. 1, p. 3, 2014.

[89] R. F. Furchgott and J. V. Zawadzki, "The obligatory role of endothelial cells in the relaxation of arterial smooth muscle by acetylcholine," Nature, vol. 288, no. 5789, pp. 373-376, 1980.

[90] M. W. Radomski, R. M. Palmer, and S. Moncada, "Endogenous nitric oxide inhibits human platelet adhesion to vascular endothelium," Lancet, vol. 2, no. 8567, pp. 1057-1058, 1987.

[91] U. C. Garg and A. Hassid, "Nitric oxide-generating vasodilators and 8-bromo-cyclic guanosine monophosphate inhibit mitogenesis and proliferation of cultured rat vascular smooth muscle cells," The Journal of Clinical Investigation, vol. 83, no. 5, pp. 1774-1777, 1989.

[92] S. Moncada, A. G. Herman, E. A. Higgs, and J. R. Vane, "Differential formation of prostacyclin (PGX or PGI2) by layers of the arterial wall. An explanation for the anti-thrombotic properties of vascular endothelium," Thrombosis Research, vol. 11, no. 3, pp. 323-344, 1977.

[93] P. Pacher, J. S. Beckman, and L. Liaudet, "Nitric oxide and peroxynitrite in health and disease," Physiological Reviews, vol. 87, no. 1, pp. 315-424, 2007.

[94] A. Görlach, R. P. Brandes, K. Nguyen, M. Amidi, F. Dehghani, and R. Busse, “A gp91phox containing NADPH 
oxidase selectively expressed in endothelial cells is a major source of oxygen radical generation in the arterial wall," Circulation Research, vol. 87, no. 1, pp. 26-32, 2000.

[95] B. Lassegue, D. Sorescu, K. Szocs et al., "Novel gp91 ${ }^{\text {phox }}$ homologues in vascular smooth muscle cells : nox1 mediates angiotensin II-induced superoxide formation and redoxsensitive signaling pathways," Circulation Research, vol. 88, no. 9, pp. 888-894, 2001.

[96] K. Bedard and K.-H. Krause, "The NOX family of ROSgenerating NADPH oxidases: physiology and pathophysiology," Physiological Reviews, vol. 87, no. 1, pp. 245-313, 2007.

[97] S. Ellmark, G. Dusting, M. Ng Tang Fui, N. Guzzo-Pernell, and G. Drummond, "The contribution of Nox4 to NADPH oxidase activity in mouse vascular smooth muscle," Cardiovascular Research, vol. 65, no. 2, pp. 495-504, 2005.

[98] K. Schröder, M. Zhang, S. Benkhoff et al., "Nox4 is a protective reactive oxygen species generating vascular NADPH oxidase," Circulation Research, vol. 110, no. 9, pp. 1217-1225, 2012.

[99] D. J. R. Fulton and S. A. Barman, "Clarity on the isoformspecific roles of NADPH oxidases and NADPH oxidase-4 in atherosclerosis," Arteriosclerosis, Thrombosis, and Vascular Biology, vol. 36, no. 4, pp. 579-581, 2016.

[100] S. P. Gray, E. Di Marco, K. Kennedy et al., "Reactive oxygen species can provide atheroprotection via NOX4-dependent inhibition of inflammation and vascular remodelingsignificance," Arteriosclerosis, Thrombosis, and Vascular Biology, vol. 36, no. 2, pp. 295-307, 2016.

[101] S. M. Craige, S. Kant, M. Reif et al., "Endothelial NADPH oxidase 4 protects ApoE-/- mice from atherosclerotic lesions," Free Radical Biology \& Medicine, vol. 89, pp. 1-7, 2015.

[102] C. Schürmann, F. Rezende, C. Kruse et al., "The NADPH oxidase Nox4 has anti-atherosclerotic functions," European Heart Journal, vol. 36, no. 48, pp. 3447-3456, 2015.

[103] H. Langbein, C. Brunssen, A. Hofmann et al., "NADPH oxidase 4 protects against development of endothelial dysfunction and atherosclerosis in LDL receptor deficient mice," European Heart Journal, vol. 37, no. 22, pp. 1753-1761, 2016.

[104] I. Takac, K. Schröder, L. Zhang et al., "The E-loop is involved in hydrogen peroxide formation by the NADPH oxidase Nox4," The Journal of Biological Chemistry, vol. 286, no. 15, pp. 13304-13313, 2011.

[105] S. M. Craige, K. Chen, Y. Pei et al., "NADPH oxidase 4 promotes endothelial angiogenesis through endothelial nitric oxide synthase activation," Circulation, vol. 124, no. 6, pp. 731-740, 2011.

[106] E. Di Marco, S. P. Gray, K. Kennedy et al., "NOX4-derived reactive oxygen species limit fibrosis and inhibit proliferation of vascular smooth muscle cells in diabetic atherosclerosis," Free Radical Biology \& Medicine, vol. 97, pp. 556-567, 2016.

[107] A. Lozhkin, A. E. Vendrov, H. Pan, S. A. Wickline, N. R. Madamanchi, and M. S. Runge, "NADPH oxidase 4 regulates vascular inflammation in aging and atherosclerosis," Journal of Molecular and Cellular Cardiology, vol. 102, pp. 10-21, 2017.

[108] C. Kleinschnitz, H. Grund, K. Wingler et al., "Post-stroke inhibition of induced NADPH oxidase type 4 prevents oxidative stress and neurodegeneration," PLoS Biology, vol. 8, no. 9, article e1000479, 2010.
[109] A. Nishimura, T. Ago, J. Kuroda et al., "Detrimental role of pericyte Nox4 in the acute phase of brain ischemia," Journal of Cerebral Blood Flow \& Metabolism, vol. 36, no. 6, pp. 1143-1154, 2016.

[110] J. Kuroda, T. Ago, S. Matsushima, P. Zhai, M. D. Schneider, and J. Sadoshima, "NADPH oxidase 4 (Nox4) is a major source of oxidative stress in the failing heart," Proceedings of the National Academy of Sciences of the United States of America, vol. 107, no. 35, pp. 15565-15570, 2010.

[111] R. M. Maalouf, A. A. Eid, Y. C. Gorin et al., "Nox4-derived reactive oxygen species mediate cardiomyocyte injury in early type 1 diabetes," American Journal of Physiology. Cell Physiology, vol. 302, no. 3, pp. C597-C604, 2012.

[112] V. Manickam, M. Periyasamy, V. Dhakshinamoorthy, L. Panneerselvam, and E. Perumal, "Recurrent exposure to ferric oxide nanoparticles alters myocardial oxidative stress, apoptosis and necrotic markers in male mice," ChemicoBiological Interactions, vol. 278, pp. 54-64, 2017.

[113] X. Sun, Y. Yang, J. Shi, C. Wang, Z. Yu, and H. Zhang, "NOX4- and Nrf2-mediated oxidative stress induced by silver nanoparticles in vascular endothelial cells," Journal of Applied Toxicology, vol. 37, no. 12, pp. 1428-1437, 2017.

[114] R. Abe, H. Takami, N. Murakami, and B. Ohtani, "Pristine simple oxides as visible light driven photocatalysts: highly efficient decomposition of organic compounds over platinumloaded tungsten oxide," Journal of the American Chemical Society, vol. 130, no. 25, pp. 7780-7781, 2008.

[115] J. Kim, C. W. Lee, and W. Choi, "Platinized WO3 as an environmental photocatalyst that generates $\mathrm{OH}$ radicals under visible light," Environmental Science \& Technology, vol. 44, no. 17, pp. 6849-6854, 2010.

[116] C. S. Kim, R. J. Lad, and C. P. Tripp, "Interaction of organophosphorous compounds with $\mathrm{TiO} 2$ and $\mathrm{WO} 3$ surfaces probed by vibrational spectroscopy," Sens. Actuators B Chem., vol. 76, no. 1-3, pp. 442-448, 2001.

[117] H. R. Petty, "Could nanoparticles that mimic the NADPH oxidase be used to kill tumor cells?," Nanomedicine, vol. 11, no. 13, pp. 1631-1634, 2016.

[118] R. M. J. Palmer, D. D. Rees, D. S. Ashton, and S. Moncada, "L-arginine is the physiological precursor for the formation of nitric oxide in endothelium-dependent relaxation," Biochemical and Biophysical Research Communications, vol. 153, no. 3, pp. 1251-1256, 1988.

[119] R. Veelken, K. F. Hilgers, A. Hartner, A. Haas, K. P. Böhmer, and R. B. Sterzel, "Nitric oxide synthase isoforms and glomerular hyperfiltration in early diabetic nephropathy," Journal of the American Society Nephrology, vol. 11, no. 1, pp. 71-79, 2000.

[120] P. Etienne, N. Parés-Herbuté, and L. Monnier, “Enhanced antiproliferative effect of nitric oxide in cultured smooth muscle cells from diabetic rats," Journal of Cardiovascular Pharmacology, vol. 27, no. 1, pp. 140-146, 1996.

[121] S. Kawashima and M. Yokoyama, "Dysfunction of endothelial nitric oxide synthase and atherosclerosis," Arteriosclerosis, Thrombosis, and Vascular Biology, vol. 24, no. 6, pp. 998-1005, 2004.

[122] S. A. Waldman and F. Murad, "Biochemical mechanisms underlying vascular smooth muscle relaxation: the guanylate cyclase-cyclic GMP system," Journal of Cardiovascular Pharmacology, vol. 12, Supplement 5, pp. S115-S118, 1988. 
[123] H. Li and U. Förstermann, "Uncoupling of endothelial NO synthase in atherosclerosis and vascular disease," Current Opinion in Pharmacology, vol. 13, no. 2, pp. 161-167, 2013.

[124] H. Li, S. Horke, and U. Förstermann, "Oxidative stress in vascular disease and its pharmacological prevention," Trends in Pharmacological Sciences, vol. 34, no. 6, pp. 313-319, 2013.

[125] U. Förstermann and T. Münzel, "Endothelial nitric oxide synthase in vascular disease: from marvel to menace," Circulation, vol. 113, no. 13, pp. 1708-1714, 2006.

[126] C. Demougeot, A. Prigent-Tessier, T. Bagnost et al., “Time course of vascular arginase expression and activity in spontaneously hypertensive rats," Life Sciences, vol. 80, no. 12, pp. 1128-1134, 2007.

[127] S. Rodriguez, L. Richert, and A. Berthelot, "Increased arginase activity in aorta of mineralocorticoid-salt hypertensive rats," Clinical and Experimental Hypertension, vol. 22, no. 1, pp. 75-85, 2000.

[128] F. K. Johnson, R. A. Johnson, K. J. Peyton, and W. Durante, "Arginase inhibition restores arteriolar endothelial function in Dahl rats with salt-induced hypertension," American Journal of Physiology. Regulatory, Integrative and Comparative Physiology, vol. 288, no. 4, pp. R1057-R1062, 2005.

[129] U. Landmesser, S. Dikalov, S. R. Price et al., "Oxidation of tetrahydrobiopterin leads to uncoupling of endothelial cell nitric oxide synthase in hypertension," The Journal of Clinical Investigation, vol. 111, no. 8, pp. 1201-1209, 2003.

[130] K. K. Galougahi, C. C. Liu, C. Gentile et al., "Glutathionylation mediates angiotensin II-induced eNOS uncoupling, amplifying NADPH oxidase-dependent endothelial dysfunction," Journal of the American Heart Association, vol. 3, no. 2, article e000731, 2014.

[131] M. A. Ramirez-Lee, P. Aguirre-Bañuelos, P. P. MartinezCuevas et al., "Evaluation of cardiovascular responses to silver nanoparticles (AgNPs) in spontaneously hypertensive rats," Nanomedicine: Nanotechnology, Biology and Medicine, vol. 14, no. 2, pp. 385-395, 2018.

[132] D. Q. Le, A. E. Kuriakose, D. X. Nguyen, K. T. Nguyen, and S. Acharya, "Hybrid nitric oxide donor and its carrier for the treatment of peripheral arterial diseases," Scientific Reports, vol. 7, no. 1, p. 8692, 2017.

[133] R. Hille and T. Nishino, "Flavoprotein structure and mechanism. 4. Xanthine oxidase and xanthine dehydrogenase," The FASEB Journal, vol. 9, no. 11, pp. 995-1003, 1995.

[134] C. Enroth, B. T. Eger, K. Okamoto, T. Nishino, T. Nishino, and E. F. Pai, "Crystal structures of bovine milk xanthine dehydrogenase and xanthine oxidase: structure-based mechanism of conversion," Proceedings of the National Academy of Sciences of the United States of America, vol. 97, no. 20, pp. 10723-10728, 2000.

[135] T. Nishino, K. Okamoto, B. T. Eger, E. F. Pai, and T. Nishino, "Mammalian xanthine oxidoreductase-mechanism of transition from xanthine dehydrogenase to xanthine oxidase," The FEBS Journal, vol. 275, no. 13, pp. 3278-3289, 2008.

[136] J. Nomura, N. Busso, A. Ives et al., "Xanthine oxidase inhibition by febuxostat attenuates experimental atherosclerosis in mice," Scientific Reports, vol. 4, no. 1, p. 4554, 2014.

[137] A. K. Shukla, C. Reinhart, and H. Michel, "Comparative analysis of the human angiotensin II type 1a receptor heterologously produced in insect cells and mammalian cells,"
Biochemical and Biophysical Research Communications, vol. 349, no. 1, pp. 6-14, 2006.

[138] C. D. Gatti, E. Osto, A. Kouroedov et al., "Pulsatile stretch induces release of angiotensin II and oxidative stress in human endothelial cells: effects of ACE inhibition and AT1 receptor antagonism," Clinical and Experimental Hypertension, vol. 30, no. 7, pp. 616-627, 2009.

[139] K. Yayama, H. Hiyoshi, D. Imazu, and H. Okamoto, “Angiotensin II stimulates endothelial NO synthase phosphorylation in thoracic aorta of mice with abdominal aortic banding via type 2 receptor," Hypertension, vol. 48, no. 5, pp. 958-964, 2006.

[140] I. H. Schulman and L. Raij, "The angiotensin II type 2 receptor: what is its clinical significance?," Current Hypertension Reports, vol. 10, no. 3, pp. 188-193, 2008.

[141] R. Hennig, K. Pollinger, J. Tessmar, and A. Goepferich, "Multivalent targeting of AT1 receptors with angiotensin II-functionalized nanoparticles," Journal of Drug Targeting, vol. 23, no. 7-8, pp. 681-689, 2015.

[142] T. Yu, S. Zhao, Z. Li et al., "Enhanced and extended antihypertensive effect of VP5 nanoparticles," International Journal of Molecular Sciences, vol. 17, no. 12, 2016.

[143] M. C. Carreras, M. Clara Franco, D. P. Converso, P. Finocchieto, S. Galli, and J. José Poderoso, "Cell $\mathrm{H} 2 \mathrm{O} 2$ steady-state concentration and mitochondrial nitric oxide," Methods in Enzymology, vol. 396, pp. 399-414, 2005.

[144] A. Boveris, L. E. Costa, E. Cadenas, and J. J. Poderoso, “[20] Regulation of mitochondrial respiration by adenosine diphosphate, oxygen, and nitric oxide," in Methods in Enzymology, vol. 301, pp. 188-198, Academic Press, 1999.

[145] N. L. Reynaert, K. Ckless, S. H. Korn et al., "Nitric oxide represses inhibitory $\kappa \mathrm{B}$ kinase through S-nitrosylation," Proceedings of the National Academy of Sciences, vol. 101, no. 24, pp. 8945-8950, 2004.

[146] L. E. Costa, G. Mendez, and A. Boveris, "Oxygen dependence of mitochondrial function measured by high-resolution respirometry in long-term hypoxic rats," American Journal of Physiology-Cell Physiology, vol. 273, no. 3, pp. C852-C858, 1997.

[147] M. C. Carreras and J. J. Poderoso, "Mitochondrial nitric oxide in the signaling of cell integrated responses," American Journal of Physiology-Cell Physiology, vol. 292, no. 5, pp. C1569C1580, 2007.

[148] M. C. Franco, V. G. A. Arciuch, J. G. Peralta et al., "Hypothyroid phenotype is contributed by mitochondrial complex I inactivation due to translocated neuronal nitric-oxide synthase," The Journal of Biological Chemistry, vol. 281, no. 8, pp. 4779-4786, 2006.

[149] T. Persichini, V. Mazzone, F. Polticelli et al., "Mitochondrial type I nitric oxide synthase physically interacts with cytochrome c oxidase," Neuroscience Letters, vol. 384, no. 3, pp. 254-259, 2005.

[150] J. Boczkowski, C. L. Lisdero, S. Lanone, M. C. Carreras, M. Aubier, and J. J. Poderoso, "Peroxynitrite-mediated mitochondrial dysfunction," Neurosignals, vol. 10, no. 1-2, pp. 66-80, 2001.

[151] M. Corral-Debrinski, J. M. Shoffner, M. T. Lott, and D. C. Wallace, "Association of mitochondrial DNA damage with aging and coronary atherosclerotic heart disease," Mutation Research, vol. 275, no. 3-6, pp. 169-180, 1992. 
[152] J. Niu, K. Wang, and P. E. Kolattukudy, "Cerium oxide nanoparticles inhibits oxidative stress and nuclear factor- $\kappa \mathrm{B}$ activation in $\mathrm{H} 9 \mathrm{c} 2$ cardiomyocytes exposed to cigarette smoke extract," The Journal of Pharmacology and Experimental Therapeutics, vol. 338, no. 1, pp. 53-61, 2011.

[153] E. L. Schiffrin, "A critical review of the role of endothelial factors in the pathogenesis of hypertension," Journal of Cardiovascular Pharmacology, vol. 38, pp. S3-S6, 2001.

[154] A. Ito, P. S. Tsao, S. Adimoolam, M. Kimoto, T. Ogawa, and J. P. Cooke, "Novel mechanism for endothelial dysfunction: dysregulation of dimethylarginine dimethylaminohydrolase," Circulation, vol. 99, no. 24, pp. 3092-3095, 1999.

[155] V. Ullrich, A. Daiber, M. Bachschmid, and M.-H. Zou, "Nitration of prostacyclin synthase: mechanism and physiological implications," International Congress Series, vol. 1233, pp. 405-414, 2002.

[156] N. Akbar, T. Mohamed, D. Whitehead, and M. Azzawi, "Biocompatibility of amorphous silica nanoparticles: size and charge effect on vascular function, in vitro," Biotechnology and Applied Biochemistry, vol. 58, no. 5, pp. 353-362, 2011.

[157] A. Farooq, D. Whitehead, and M. Azzawi, "Attenuation of endothelial-dependent vasodilator responses, induced by dye-encapsulated silica nanoparticles, in aortic vessels," Nanomedicine, vol. 9, no. 3, pp. 413-425, 2014.

[158] C. Guo, J. Wang, L. Jing et al., "Mitochondrial dysfunction, perturbations of mitochondrial dynamics and biogenesis involved in endothelial injury induced by silica nanoparticles," Environmental Pollution, vol. 236, pp. 926-936, 2018.

[159] V. C. Minarchick, P. A. Stapleton, E. M. Sabolsky, and T. R. Nurkiewicz, "Cerium dioxide nanoparticle exposure improves microvascular dysfunction and reduces oxidative stress in spontaneously hypertensive rats," Frontiers in Physiology, vol. 6, p. 339, 2015.

[160] C. Korsvik, S. Patil, S. Seal, and W. T. Self, "Superoxide dismutase mimetic properties exhibited by vacancy engineered ceria nanoparticles," Chemical Communications, no. 10, pp. 1056-1058, 2007.

[161] J. Niu, A. Azfer, L. Rogers, X. Wang, and P. Kolattukudy, "Cardioprotective effects of cerium oxide nanoparticles in a transgenic murine model of cardiomyopathy," Cardiovascular Research, vol. 73, no. 3, pp. 549-559, 2007.

[162] C. J. Wingard, D. M. Walters, B. L. Cathey et al., "Mast cells contribute to altered vascular reactivity and ischemiareperfusion injury following cerium oxide nanoparticle instillation," Nanotoxicology, vol. 5, no. 4, pp. 531-545, 2011.

[163] V. C. Minarchick, P. A. Stapleton, N. R. Fix, S. S. Leonard, E. M. Sabolsky, and T. R. Nurkiewicz, "Intravenous and gastric cerium dioxide nanoparticle exposure disrupts microvascular smooth muscle signaling," Toxicological Sciences, vol. 144, no. 1, pp. 77-89, 2015.

[164] A. Gojova, J.-T. Lee, H. S. Jung, B. Guo, A. I. Barakat, and I. M. Kennedy, "Effect of cerium oxide nanoparticles on inflammation in vascular endothelial cells," Inhalation Toxicology, vol. 21, Supplement 1, pp. 123-130, 2009.

[165] I. M. Kennedy, D. Wilson, and A. I. Barakat, "Uptake and inflammatory effects of nanoparticles in a human vascular endothelial cell line," Research Report, no. 136, pp. 3-32, 2009.

[166] P. Strålin, K. Karlsson, B. O. Johansson, and S. L. Marklund, "The interstitium of the human arterial wall contains very large amounts of extracellular superoxide dismutase," Arteriosclerosis, Thrombosis, and Vascular Biology, vol. 15, no. 11, pp. 2032-2036, 1995.

[167] T. Fukai and M. Ushio-Fukai, "Superoxide dismutases: role in redox signaling, vascular function, and diseases," Antioxidants \& Redox Signaling, vol. 15, no. 6, pp. 1583-1606, 2011.

[168] D. L. Tribble, E. L. Gong, C. Leeuwenburgh et al., "Fatty streak formation in fat-fed mice expressing human copperzinc superoxide dismutase," Arteriosclerosis, Thrombosis, and Vascular Biology, vol. 17, no. 9, pp. 1734-1740, 1997.

[169] S. Nelson, S. Bose, and J. McCord, "The toxicity of high-dose superoxide dismutase suggests that superoxide can both initiate and terminate lipid peroxidation in the reperfused heart," Free Radical Biology \& Medicine, vol. 16, no. 2, pp. 195-200, 1994.

[170] B. Halliwell, M. V. Clement, and L. H. Long, "Hydrogen peroxide in the human body," FEBS Letters, vol. 486, no. 1, pp. 10-13, 2000.

[171] K. S. Kim, C. G. Song, and P. M. Kang, "Targeting oxidative stress using nanoparticles as a theranostic strategy for cardiovascular diseases," Antioxidants \& Redox Signaling, 2018.

[172] A. Jain, N. Mehra, and N. Swarnakar, "Role of antioxidants for the treatment of cardiovascular diseases: challenges and opportunities," Current Pharmaceutical Design, vol. 21, no. 30, pp. 4441-4455, 2015.

[173] Y. Wang, G. Z. Wang, P. S. Rabinovitch, and I. Tabas, "Macrophage mitochondrial oxidative stress promotes atherosclerosis and nuclear factor- $\kappa \mathrm{B}$-mediated inflammation in macrophages," Circulation Research, vol. 114, no. 3, pp. 421-433, 2014.

[174] A. Pratsinis, G. A. Kelesidis, S. Zuercher et al., "Enzymemimetic antioxidant luminescent nanoparticles for highly sensitive hydrogen peroxide biosensing," ACS Nano, vol. 11, no. 12, pp. 12210-12218, 2017.

[175] A. Meister and M. E. Anderson, "Glutathione," Annual Review of Biochemistry, vol. 52, no. 1, pp. 711-760, 1983.

[176] E. Lubos, J. Loscalzo, and D. E. Handy, "Glutathione peroxidase- 1 in health and disease: from molecular mechanisms to therapeutic opportunities," Antioxidants \& Redox Signaling, vol. 15, no. 7, pp. 1957-1997, 2011.

[177] S. Blankenberg, H. J. Rupprecht, C. Bickel et al., "Glutathione peroxidase 1 activity and cardiovascular events in patients with coronary artery disease," The New England Journal of Medicine, vol. 349, no. 17, pp. 1605-1613, 2003.

[178] J. Lu and A. Holmgren, "The thioredoxin antioxidant system," Free Radical Biology \& Medicine, vol. 66, pp. 75-87, 2014.

[179] S. W. Kang, H. Z. Chae, M. S. Seo, K. Kim, I. C. Baines, and S. G. Rhee, "Mammalian peroxiredoxin isoforms can reduce hydrogen peroxide generated in response to growth factors and tumor necrosis factor- $\alpha$," The Journal of Biological Chemistry, vol. 273, no. 11, pp. 6297-6302, 1998.

[180] M. Okuda, N. Inoue, H. Azumi et al., "Expression of glutaredoxin in human coronary arteries: its potential role in antioxidant protection against atherosclerosis," Arteriosclerosis, Thrombosis, and Vascular Biology, vol. 21, no. 9, pp. 14831487, 2001.

[181] H. Nakamura, M. Matsuda, K. Furuke et al., "Adult T cell leukemia-derived factor/human thioredoxin protects endothelial F-2 cell injury caused by activated neutrophils or 
hydrogen peroxide," Immunology Letters, vol. 42, no. 1-2, pp. 75-80, 1994.

[182] Y. Takagi, Y. Gon, T. Todaka et al., "Expression of thioredoxin is enhanced in atherosclerotic plaques and during neointima formation in rat arteries," Laboratory Investigation, vol. 78, no. 8, pp. 957-966, 1998.

[183] J. Fujii and Y. Ikeda, “Advances in our understanding of peroxiredoxin, a multifunctional, mammalian redox protein," Redox Report, vol. 7, no. 3, pp. 123-130, 2013.

[184] L. Iuliano, "The oxidant stress hypothesis of atherogenesis," Lipids, vol. 36, Supplement 1, pp. S41-S44, 2001.

[185] J. Fujii, Y. Ikeda, T. Kurahashi, and T. Homma, "Physiological and pathological views of peroxiredoxin 4," Free Radical Biology \& Medicine, vol. 83, pp. 373-379, 2015.

[186] H. Jakubowski, "The role of paraoxonase 1 in the detoxification of homocysteine thiolactone," in Paraoxonases in Inflammation, Infection, and Toxicology, pp. 113-127, Humana Press, 2010.

[187] S. Park, J. Yoon, S. Bae et al., "Therapeutic use of $\mathrm{H}_{2} \mathrm{O}_{2}$-responsive anti-oxidant polymer nanoparticles for doxorubicininduced cardiomyopathy," Biomaterials, vol. 35, no. 22, pp. 5944-5953, 2014.

[188] F. Danhier, O. Feron, and V. Préat, "To exploit the tumor microenvironment: passive and active tumor targeting of nanocarriers for anti-cancer drug delivery," Journal of Controlled Release, vol. 148, no. 2, pp. 135-146, 2010.

[189] G. Seshadri, J. C. Sy, M. Brown et al., "The delivery of superoxide dismutase encapsulated in polyketal microparticles to rat myocardium and protection from myocardial ischemiareperfusion injury," Biomaterials, vol. 31, no. 6, pp. 13721379, 2010.

[190] X. Chen, L. Liu, and C. Jiang, "Charge-reversal nanoparticles: novel targeted drug delivery carriers," Acta Pharmaceutica Sinica B, vol. 6, no. 4, pp. 261-267, 2016.

[191] C. Xu and X. Qu, "Cerium oxide nanoparticle: a remarkably versatile rare earth nanomaterial for biological applications," NPG Asia Materials, vol. 6, no. 3, article e90, 2014. 


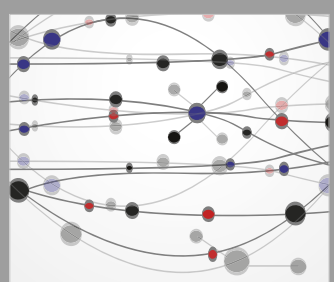

The Scientific World Journal
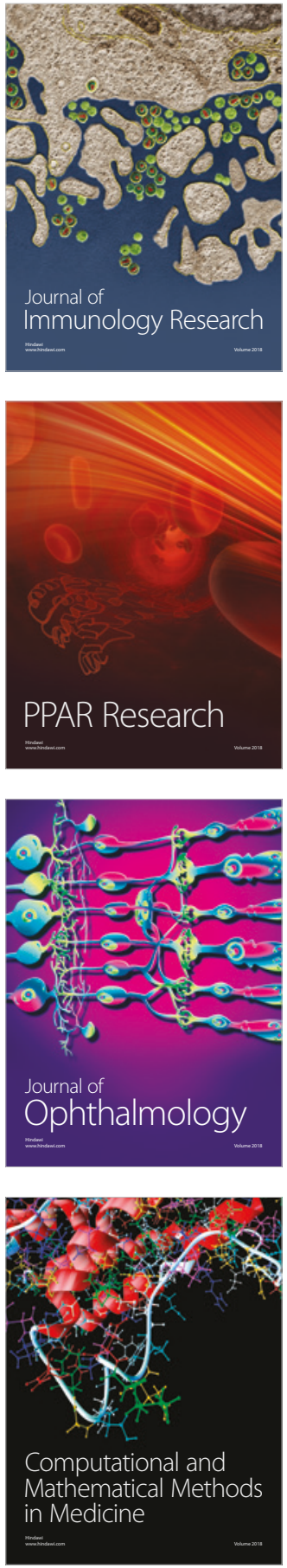

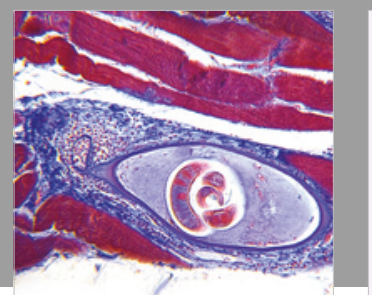

Gastroenterology Research and Practice

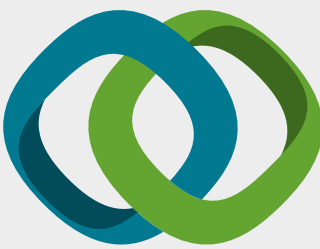

\section{Hindawi}

Submit your manuscripts at

www.hindawi.com
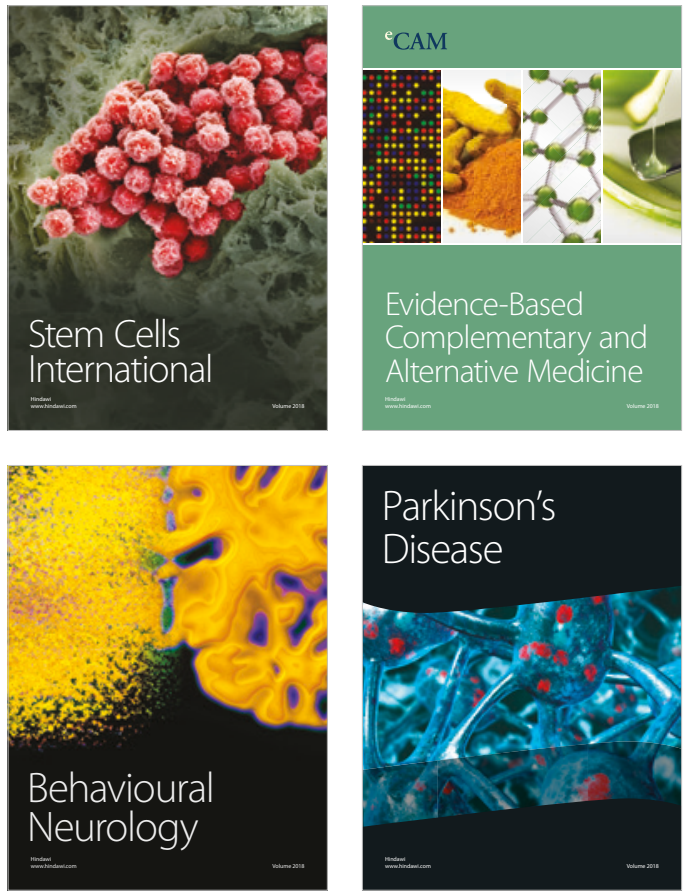

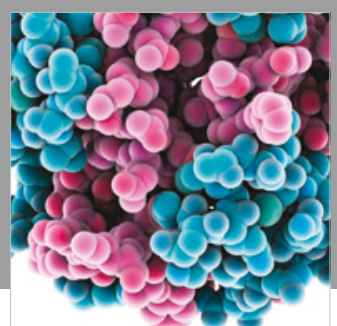

ournal of

Diabetes Research

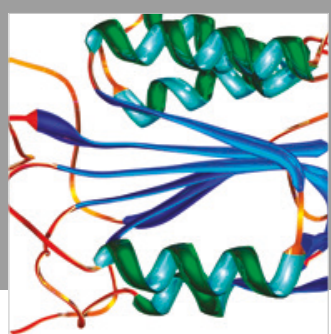

Disease Markers
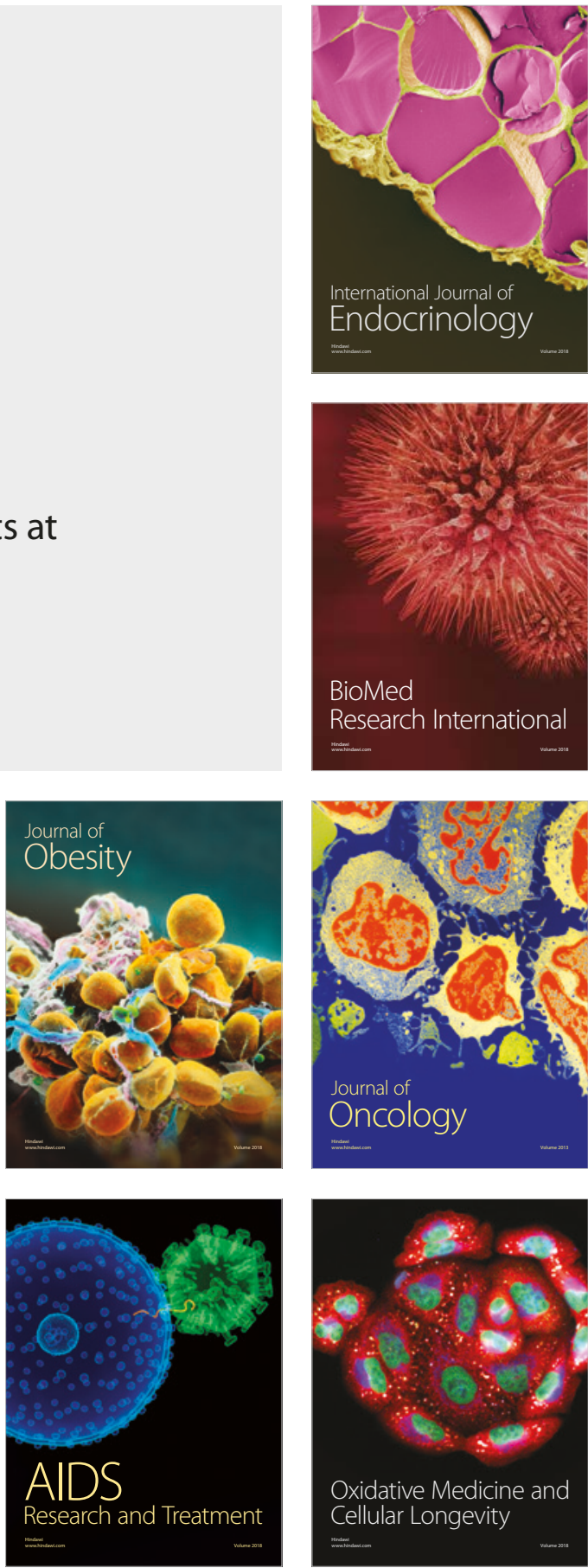